\title{
Crust and upper mantle of Kamchatka from teleseismic receiver functions
}

\author{
Vadim Levin $^{\mathrm{a}, *}$, Jeffrey Park ${ }^{\mathrm{a}}$, Mark Brandon ${ }^{\mathrm{a}}$, Jonathan Lees ${ }^{\mathrm{a}, 1}$, \\ Valerie Peyton ${ }^{\mathrm{a}, 2}$, Evgenii Gordeev ${ }^{\mathrm{b}}$, Alexei Ozerov ${ }^{\mathrm{b}}$ \\ ${ }^{a}$ Department of Geology and Geophysics, Yale University, P.O. Box 208109, 06520-8109 New Haven, CT, USA \\ ${ }^{\mathrm{b}}$ Russian Academy of Sciences, Far Eastern Branch, Petropavlovsk-Kamchatsky, Russia
}

Received 21 November 2000; received in revised form 15 April 2001; accepted 15 June 2002

\begin{abstract}
Teleseismic receiver functions (RFs) from a yearlong broadband seismological experiment in Kamchatka reveal regional variations in the Moho, anisotropy in the supra-slab mantle wedge, and, along the eastern coast, $P s$ converted phases from the steeply dipping slab. We analyze both radial- and transverse-component RFs in bin-averaged epicentral and backazimuthal sweeps, in order to detect $P s$ moveout and polarity variations diagnostic of interface depth, interface dip, and anisotropic fabric within the shallow mantle and crust. At some stations, the radial RF is overprinted by near-surface resonances, but anisotropic structure can be inferred from the transverse RF. Using forward modeling to match the observed RFs, we find Moho depth to range between 30 and $40 \mathrm{~km}$ across the peninsula, with a gradational crust-mantle transition beneath some stations along the eastern coast. Anisotropy beneath the Moho is required to fit the transverse RFs at most stations. Anisotropy in the lower crust is required at a minority of stations. Modeling the amplitude and backazimuthal variation of the $P s$ waveform suggests that an inclined axis of symmetry and $5-10 \%$ anisotropy are typical for the crust and the shallow mantle. The apparent symmetry axes of the anisotropic layers are typically trench-normal, but trench-parallel symmetry axes are found for stations APA and ESS, both at the fringes of the central Kamchatka depression. Transverse RFs from east-coast stations KRO, TUM, ZUP and PET are fit well by two anisotropic mantle layers with trench-normal symmetry axes and opposing tilts. Strong anisotropy in the supraslab mantle wedge suggests that the mantle "lithosphere" beneath the Kamchatka volcanic arc is actively deforming, strained either by wedge corner flow at depth or by trenchward suction of crust as the Pacific slab retreats.
\end{abstract}

(C) 2002 Elsevier Science B.V. All rights reserved.

Keywords: Crust; Upper mantle; Kamchatka

\section{Introduction}

${ }^{*}$ Corresponding author. Tel.: +1-203-432-3114; fax: +1-203432-3134.

E-mail address: vadim@1deo.columbia.edu (V. Levin).

${ }^{1}$ Now at University of North Carolina, Chapel Hill, NC, USA.

2 Now at US Geological Survey, Albuquerque, NM, USA.
Kamchatka is one of the few places in the world where land-based observations can be used to probe the upper mantle at and beyond the side edge of a mature subducting slab. A subduction zone underlies southern Kamchatka, terminating at the junction with 
the Aleutian Arc (Fig. 1), where the Pacific plate boundary rotates into a transcurrent shear zone (Cormier, 1975). Kamchatka and eastern Siberia constitute the western extremity of the North American Plate (Fujita et al., 1990; DeMets, 1992; Kogan et al., 2000). Rapid convergence $(60-80 \mathrm{~mm} / \mathrm{year})$ of the Pacific plate relative to North America is accommo-

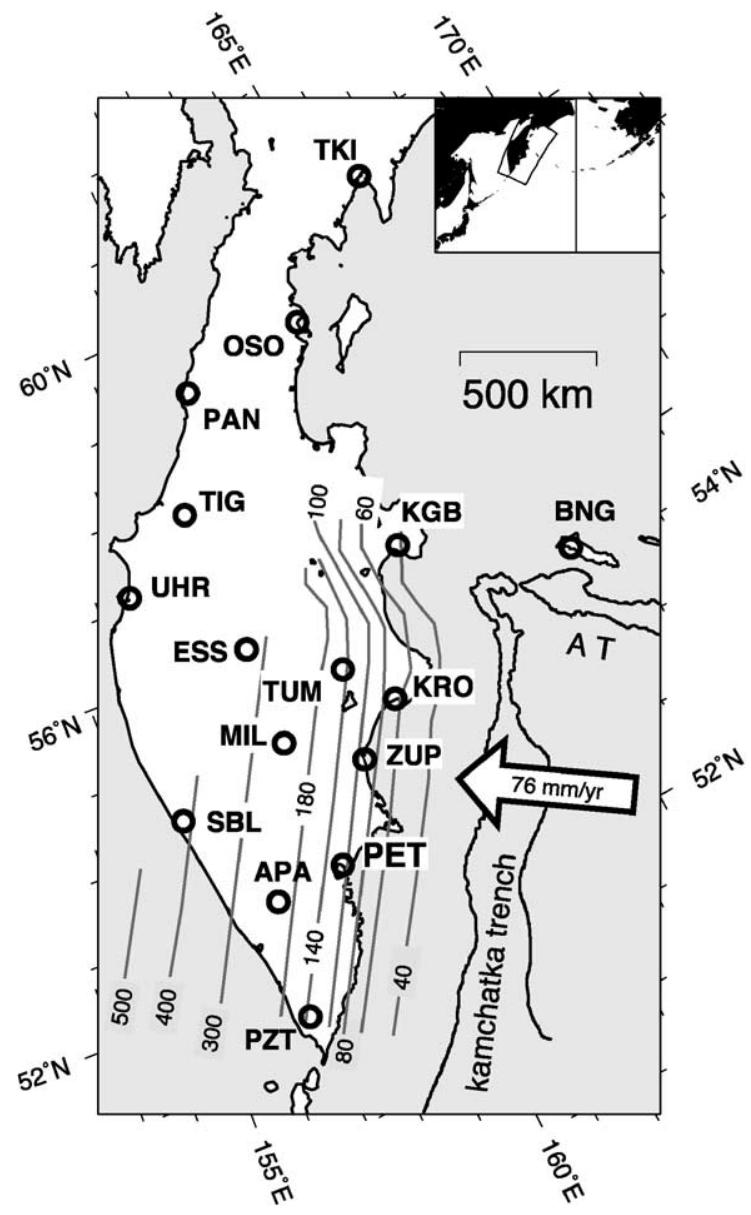

Fig. 1. Map of the region of study. Locations of portable seismic observatories are shown by open circles with three-letter tags. PET denotes the Global Seismographic Network station in the city of Petropavlovsk-Kamchatsky. For detailed information about portable deployment see http://www.passcal.nmk.edu. Open arrow shows the direction of convergence along the Kamchatka trench. Thin black lines in the ocean denote the depth contour of $5500 \mathrm{~m}$, providing an outline of the Kamchatka and Aleutian deep-water trenches. Subducting slab configuration is shown by a set of isodepth lines adapted from Gorbatov et al. (1997). An inset shows the study region within the northwestern Pacific. A straight line on the inset denotes longitude of $180^{\circ}$. dated by subduction zones that flank the Aleutian, Kamchatka and Kurile volcanic arcs (Fig. 1, inset). Both subduction and island-arc volcanism are interrupted by the strike-slip Bering fault zone along the western Aleutians (Komandorski Islands) (Geist and Scholl, 1994; Seliverstov, 1997). The western Aleutians terminate against Cape Kamchatka at $56 \mathrm{~N}$. The plate boundary extends southward as a convergent Benioff zone, but shallow historical seismicity also extends $\sim 300 \mathrm{~km}$ northward (Fujita et al., 1990), suggesting deformation complexities. Near the Kamchatka-Aleutian corner, the subduction zone lacks deep earthquakes, and Benioff-zone dip decreases from 55 to 35 (Gorbatov et al, 1997). Active volcanism shifts inland to follow the shallowing slab, terminating in the vigorous Klyuchevskoy and Sheveluch volcanic centers.

Although convergent trench-arc boundaries are the most seismically active portions of the global system of tectonic plates, our knowledge of them has significant gaps. Widely held conceptual models for the structure and dynamics of the descending slab and the supra-slab "mantle wedge" are not fully buttressed by observations. For instance, when oceanic lithosphere subducts into the mantle, it may undergo trench-axis rollback (Dewey, 1980; Otsuki, 1989), in which the mantle under the slab is forced out of the way, either downward or along the trench towards a "free" end of the subduction zone (Russo and Silver, 1994). The most common geodynamic model for the supra-slab mantle wedge involves flow induced by shear-coupling to the descending slab (e.g., Ida, 1983). Both types of motion should induce elastic anisotropy in the upper mantle peridotite, as a result of the latticepreferred orientation (LPO) of olivine and orthopyroxene crystals in peridotite (Christensen, 1984; Ribe, 1992; Zhang and Karato, 1995; Zhang et al., 2000). Trench-parallel flow beneath the subducting slab has been proposed for a variety of convergent settings (Alvarez, 1982; Giardini and Woodhouse, 1986) and has found support in measurements of seismic anisotropy (Russo and Silver, 1994; Yu and Park, 1994; Peyton et al., 2001). Corner flow in the supra-slab mantle-wedge would induce a trench-normal anisotropic fast polarization. However, weak shear-wave splitting in the mantle wedge is commonly observed where back-arc spreading is weak (Fischer et al., 1998; Weimer et al., 1999; Peyton et al., 2001), and 
trench-parallel fast polarization has been found in New Zealand (Marson-Pidgeon et al., 1999) and the Oregon Cascades (Yuan et al., submitted for publication), where subduction is oblique. A weakly developed corner flow in the mantle wedge is consistent with the tank experiments of Buttles and Olson (1998).

Crustal structure in volcanic arcs may also offer clues to the creation of continental lithosphere, often assumed to be distilled from the mantle by subduction-zone volcanism. Continental crust has classically been divided into "felsic" upper and "mafic" lower layers. Although this division has long been recognized as an oversimplification (Mueller, 1977), a distinct velocity jump between upper and lower crust has been identified in many locales (e.g., Mooney et al., 1985; Zhu and Ebel, 1994). Does this distinction hold in the subduction-zone environment, or does it develop later via mafic underplating, e.g., as a result of post-collisional mantle delamination or rollback (Bird, 1979; Conrad and Molnar, 1997; Willett and Beaumont, 1994)? Are there anisotropic structures in the crust that suggest independent modes of deformation above and below the Moho?

Shallow variations in anisotropic parameters can generate $P$-to- $S$ converted waves in the coda of teleseismic $P$ waves. Converted waves can be detected and characterized with the receiver-function (RF) technique (Langston, 1977a,b; Ammon, 1991; Park and Levin, 2000). Anisotropic layering in the crust and shallow mantle has been identified on the basis of Ps amplitude variation, with backazimuth, in the transverse-component receiver function (Bostock, 1998; Levin and Park, 1997a,b; 2000; Savage, 1998). We apply RF analysis to data from a temporary broadband seismic array in Kamchatka. Our objective is to detect anisotropic shear zones in the crust of the upper plate, and within the supra-slab mantle wedge. Localized shear zones in the mantle wedge may develop as a result of nonlinear olivine rheology (Karato and $\mathrm{Wu}, 1993$ ) or the reduction of viscosity by volatiles expelled from the slab (Hirth and Kohlstedt, 1996). Either of these effects might decrease the shear coupling of the slab and mantle wedge, and retard the development of corner flow.

In the next sections we describe previous seismological investigations of Kamchatka, and provide brief descriptions of the multi-taper correlation (MTC) algorithm for RF-estimation, and the data interpretation technique. Receiver functions at individual stations of the portable network, augmented by the permanent station PET (Petropavlovsk-Kamchatsky) of the Global Seismographic Network (GSN), are presented in Section 4, with a brief overview of findings in Section 5. Section 6 discusses general features of our results and their implications.

\section{Previous seismic studies in Kamchatka}

Establishment of an earthquake monitoring network in Kamchatka in the early 1960s (Fedotov et al., 1964) provided the basis for early studies of the seismic structure of the Kamchatka lithosphere. These investigations (e.g., Fedotov and Slavina, 1968; Kuzin, 1973; Boldyrev, 1974) relied on travel-time data from local (and teleseismic) earthquakes, and stressed lateral variability of seismic properties in the subcrustal upper mantle. The region investigated was mostly restricted to the southeast part of Kamchatka - the area covered by the network of seismic stations. Most early studies focussed on $P$-wave propagation, although Kuzin (1973) reports estimates for upper-mantle $V_{\mathrm{S}}$ as well.

A range of active source studies carried out in Kamchatka along a set of linear profiles afforded much higher resolution of the local crustal structure. These studies (e.g., Balesta et al., 1977) concentrated on two regions - near the Klyuchevskoy volcanic center, and in the vicinity of Petropavlovsk-Kamchatsky (PET in Fig. 1). Balesta and Gontovaya (1985) provide a summary of this work. Noteworthy is the difficulty of identifying the precise position of the crust-mantle transition discussed by these authors.

More recently, large-scale tomographic models of $V_{\mathrm{P}}$ and $V_{\mathrm{S}}$ were constructed for the Kamchatka Peninsula, in the context of larger studies by van der Hilst et al. (1991) and Gorbatov et al. (2000). The latter study combines regional observations with teleseismic seismicity, and provides a broad outline of the mantle structures in the region. Gorbatov et al. (1997) focus on the geometry of the subducting slab under Kamchatka, while local seismic data are used by Gorbatov et al. (1999) to image small-scale lateral variability of the crust and upper $200 \mathrm{~km}$ of the mantle under southeastern Kamchatka. Establishment of a 
broad-band seismological observatory in Petropavlovsk-Kamchatsky in 1993 facilitated a study of regional surface-wave dispersion (Shapiro et al., 2000 ), which yielded the first estimate of the $V_{S}$ structure for the entire peninsula.

\section{Data particulars and methodology}

\subsection{Observations}

We deployed 15 portable broad-band seismic observatories in Kamchatka from Summer 1998 through Summer 1999. All stations were equipped with CMG-3T sensors and REF TEK data acquisition systems. Using GPS timing, we collected data continuously at 40 samples per second. Microseisms and various types of cultural noise caused loss of some data and led to limited recording band width at several sites.

Fig. 2 depicts the geographic distribution of 98 earthquakes used in this study. $P$ waves approached our network from three main backazimuthal ranges: south $\left(140^{\circ}-260^{\circ}\right)$, northeast $\left(50^{\circ}-70^{\circ}\right)$ and westnorthwest $\left(270^{\circ}-330^{\circ}\right)$. Not all events produced usable records at every station. We also analyzed data

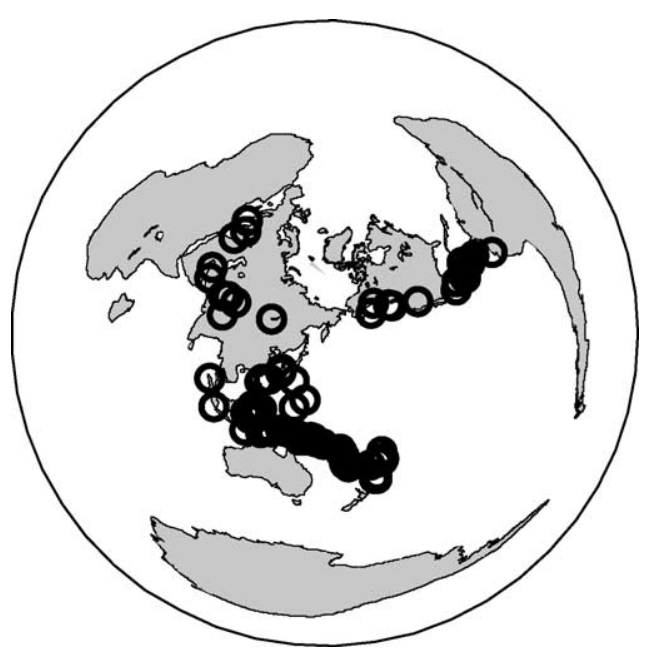

Fig. 2. Earthquakes used in receiver function analysis. Because of noise, power failures, and timing of equipment deployment/ removal, no one station recorded all 98 events shown. Most stations observed more than 20 of the earthquakes shown. from IRIS GSN station PET, which has operated nearly continuously since mid-1993.

\subsection{MTC receiver functions}

Spectral division is the simplest way to deconvolve the vertical motion of a $P$ wave from its horizontal motion, and to retrieve thereby the trailing PS converted waves that form the "receiver function" (RF) for the seismic station. These phases, arriving closely behind the "parent" $P$ wave, carry information about the structure of the medium relatively close to the observation site.

In the frequency domain, the RFs are estimated by a ratio of different component spectra:

$H_{\mathrm{R}}(f)=\frac{Y_{\mathrm{R}}(f)}{Y_{\mathrm{Z}}(f)} \quad$ and $\quad H_{\mathrm{T}}(f)=\frac{Y_{\mathrm{T}}(f)}{Y_{\mathrm{Z}}(f)}$,

where $Y_{\mathrm{R}}(f), Y_{\mathrm{T}}(f)$ and $Y_{\mathrm{Z}}(f)$ are the Fourier spectra of the radial, transverse and vertical seismic components, respectively. We use a variant on spectral division (Park and Levin, 2000) based on multi-taper correlation (MTC) (Vernon et al., 1991) to compute frequency-domain RFs, $H_{\mathrm{R}}(f)$ and $H_{\mathrm{T}}(f)$. The MTC algorithm estimates RF uncertainties from the coherence between horizontal and vertical $P$-coda motion. These uncertainties provide a useful weighting scheme for stacking RFs from different seismic records. Multi-taper spectrum estimation techniques are resistant to spectral leakage (Thomson, 1982; Park et al., 1987), so that the MTC RF-estimate can exploit low-amplitude portions of the $P$-wave spectrum that may nonetheless have a high signal-to-noise ratio.

We form composite RFs in narrow ranges of either epicentral distance or approach direction to detect fluctuations in timing and scattering of phases, respectively. Close examination of such fluctuations helps discriminate effects of interface dips, the presence of side-scattered energy and polarity patterns diagnostic of anisotropy. In our backazimuth and epicentral RF sweeps, we bin data in $10^{\circ}$ overlapping intervals at $5^{\circ}$ spacing, so each seismic record influences two adjacent bins. Single-record RFs are bin-weighted by their inverse variances in the frequency domain. An inverse Fourier transform obtains the time domain RFs, $H_{\mathrm{R}}(t)$ and $H_{\mathrm{T}}(t)$, from the weighted bin-averaged $H_{\mathrm{R}}(f)$ and $H_{\mathrm{T}}(f)$. By varying the value of the low-pass frequency 
cutoff, we can explore frequency dependencies in observed RF features. RF analyses reported here use a frequency cutoff $f_{\mathrm{c}}=1 \mathrm{~Hz}$. A cosine-squared lowpass filter is applied in the frequency domain to avoid Gibbs-effect ringing, so the effective frequency cutoff is lower, roughly $0.5 \mathrm{~Hz}$.

\subsection{Interpretation strategy}

To model our observations, we employ reflectivity calculations in one-dimensional horizontally stratified anisotropic structures (Levin and Park, 1997a,b, 1998). Waveforms obtained by stacking all RFs within a chosen backazimuthal bin are treated as "data" to be fit. We chose features of the RF to be modeled through visual inspection of RF gathers (e.g., Fig. 3a). Features are chosen on the basis of their coherence over broad ranges of approach directions, their timing as a function of source distance and their frequency content. The approach is similar to standard interpretation practices in active-source seismology (e.g., correlating reflectors on a shot gather). We devoted close attention to the partitioning of converted wave energy between $P-S V$ (radial or R) and $S H$ (transverse or T) components, as these are sensitive to different physical properties of the medium.

The objective of modeling is to find a layered onedimensional structure that yields a synthetic seismogram that captures the behavior of the chosen features in the observed data. We develop models through a trial-and-error process informed by observations of backazimuthal and epicentral behavior, predictions from the study of synthetic models (Levin and Park, 1998), knowledge of the likely properties of crustal and upper-mantle rocks, and Occam's Razor.

In developing models for observed RFs, we use radial components to constrain first-order vertical profiles of $V_{\mathrm{P}}$ and $V_{\mathrm{S}}$, and examine transverse components for evidence of seismic anisotropy and/or a dip of model interfaces. In constructing velocity profiles, we vary $V_{\mathrm{S}}$ and compute $V_{\mathrm{P}}=1.75 V_{\mathrm{S}}$. By fixing the $V_{\mathrm{P}} / V_{\mathrm{S}}$ ratio, we flatten much of the elastic variability of crustal rocks, particularly gabbroic mafic rocks, whose Poisson ratio can approach 0.3 (Christensen, 1996). However, when interpreting the primary RF observables, Ps delay time and amplitude, the effect of Poisson ratio trades off with layer thickness and anisotropic strength, respectively. For this reason we do not attempt to constrain the $V_{\mathrm{P}} / V_{\mathrm{S}}$ ratio independently from the RFs. We use backazimuthdependent polarity changes of the transverse-component $P S$ converted phases to guide our choices of anisotropic parameters. We assume that anisotropy has a hexagonal symmetry, with a "slow" axis in the crust and a "fast" axis in the mantle. Exceptions to the "slow/fast" rule are discussed for a few special cases. The proportional anisotropy of $P$ and $S$ waves is assumed to be the same.

We compute reflectivity seismograms for upgoing compressional pulses at chosen backazimuths, and with phase velocity of $20 \mathrm{~km} / \mathrm{s}$. In a standard one-dimensional Earth model, these waves have an incidence angle of $\sim 24^{\circ}$ within the subcrustal lithosphere, typical for $P$ waves from the sources $50^{\circ}-80^{\circ}$ away. We estimate RFs from these synthetics to compare with data-derived RFs, and modify the model until the waveforms are visually similar.

The inferred models of velocity distribution with depth reflect the structure under the observation site, with uncertainties imposed by data distribution and quality, and by two assumptions made in the modeling: that the structure is one-dimensional, and that the ratio of $V_{\mathrm{P}}$ to $V_{\mathrm{S}}$ is constant. Deviations from the first assumption are discussed for a few stations where $P$ waves from opposing back azimuth sectors imply two distinct crustal structures. The second assumption limits the free parameters, and also facilitates the comparison of this study with surface wave investigations by Shapiro et al. (2000). This simplification is motivated by the broad overview nature of this study. Many portable observatories acquired data that deserve in-depth analysis, and this will be the subject of further work.

\section{Receiver functions: observations and modeling}

In this section, we describe the main features of observed receiver functions at all sites. For sites where we believe that RFs offer a reliable constraint on crustal and upper mantle structure, we also present results of forward modeling of the averaged RFs, and briefly describe the reasoning by which these models were obtained. A summary of findings is presented in the following section. 
(a)

APA

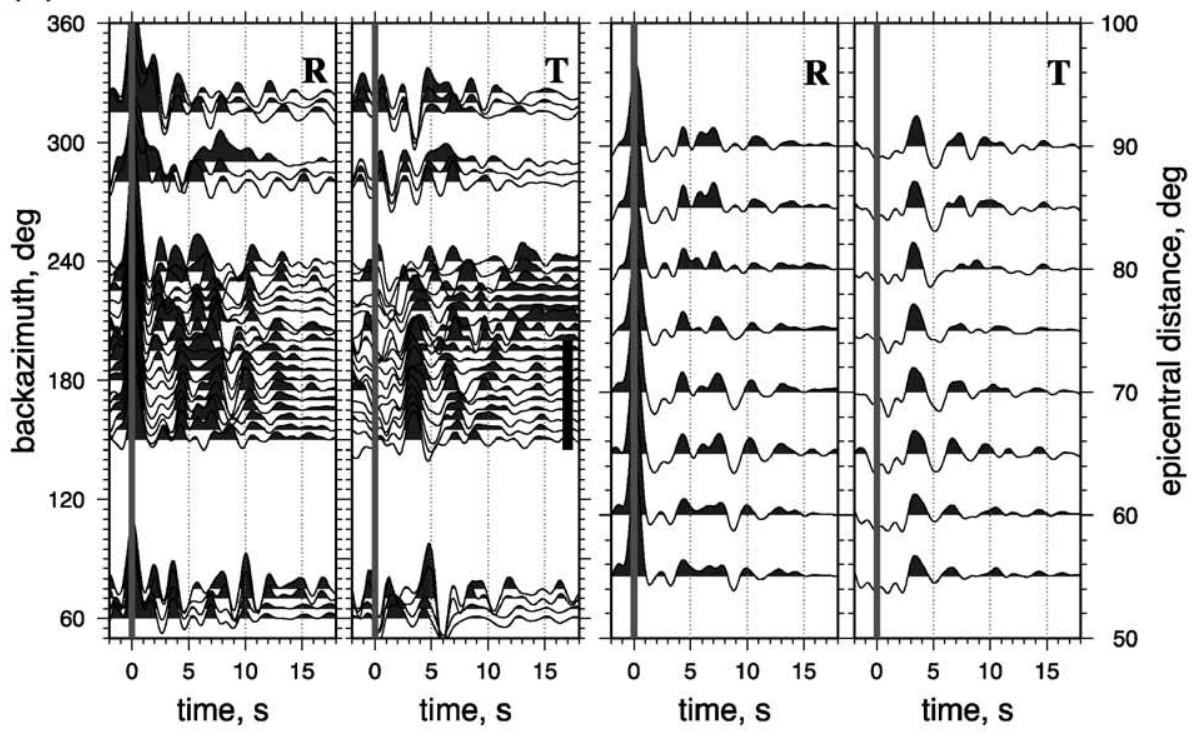

(b)
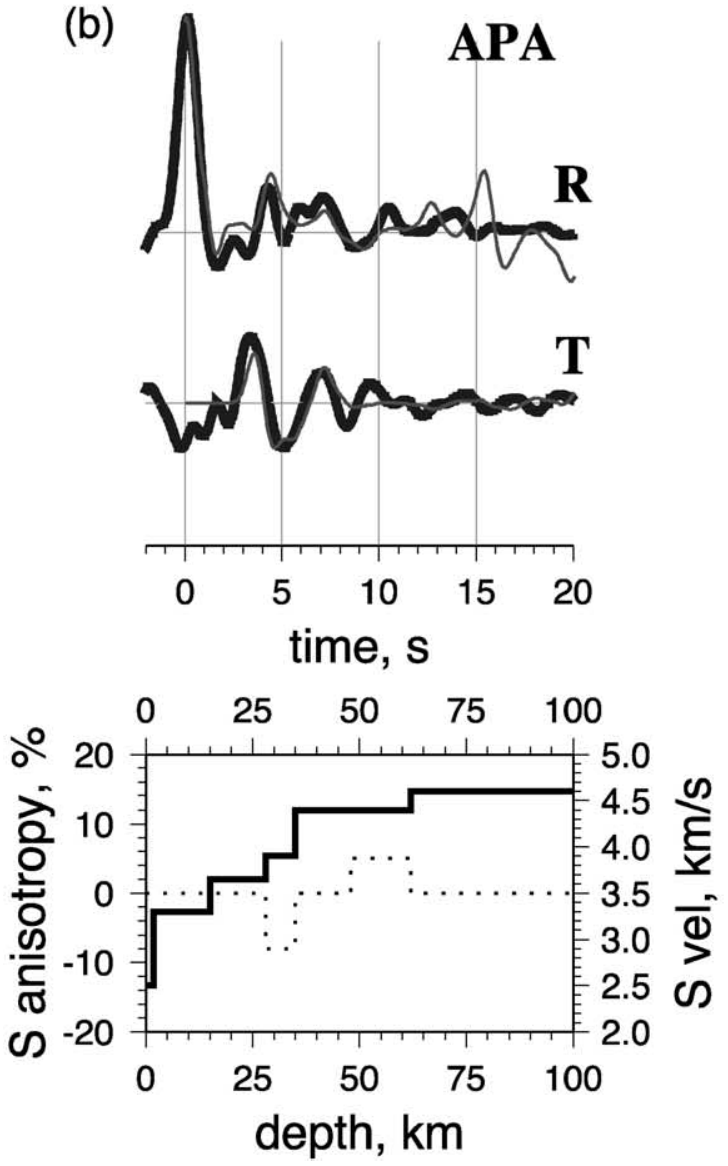
Terms commonly used throughout this section are "backazimuth" - the direction from the station towards the earthquake measured clockwise from the north, and "moveout" - change in arrival time, with distance or direction, of the phase that otherwise appears similar on adjacent records. Pulse shapes on the record are described as "one-sided" (one swing, either negative or positive) or "two-sided" (a sequence of a negative swing and a positive swing, or vice versa). We describe the geometry of anisotropy in our models by the azimuth $\varphi$ (clockwise from North) and inclination (or tilt) $\theta$, down from vertical, of symmetry axes in different layers. Anisotropy is "slow" or "fast", depending on the relative wavespeed along the symmetry axis. A common assumption in lithospheric anisotropy is that crustal anisotropy is more likely to have a slow axis of symmetry, caused by finelayering, cracks or melt lenses, while in the subcrustal mantle the axis of symmetry is likely to be fast, caused by olivine LPO in the dislocation creep of peridotite. Model parameters are not uniquely determined by data from a sparse collection of backazimuths, so alternate interpretations must be considered. There are circumstances, outlined in Discussion, for presuming the mantle to have a slow axis of symmetry. Levin and Park (1998) discuss the mathematical tradeoffs in RF interpretation.

\subsection{Central Kamchatka}

Stations located within the central part of Kamchatka (APA, MIL, ESS and TUM) were installed early in the deployment, and collected larger data sets. Noise levels at these sites were the lowest in the network.

\subsubsection{APA}

RFs obtained for station APA are shown in Fig. 3a. Useful data were obtained from all three main source regions. A positive radial phase between 4 and $5 \mathrm{~s}$ is seen clearly in backazimuthal range $145^{\circ}-220^{\circ}$. It is followed by another positive pulse between 7 and $8 \mathrm{~s}$, which shows significant changes in timing with backazimuth. A sequence of two weaker positive pulses separated by a negative is seen between 10 and $13 \mathrm{~s}$. This coherent group of phases arrives progressively later with an increase in epicenter distance, and is thus unlikely to represent a feature at depth. On the transverse component the most prominent feature is a twosided pulse between 3 and $5.5 \mathrm{~s}$, followed by a weaker positive pulse at 6-7 $\mathrm{s}$. The first two-sided pulse weakens towards backazimuth $230^{\circ}$, and reverses in backazimuthal range $310^{\circ}-330^{\circ}$, while in the $60^{\circ}-$ $75^{\circ}$ range it seems to arrive later.

Fig. 3b shows composite RFs for the southeastern backazimuthal sector, and the layered structure that produces synthetics with similar behavior. A complete description of the model is given in Table 1. The first $10 \mathrm{~s}$ of the radial RF are matched well. A broad two-sided pulse at $7-9 \mathrm{~s}$ arises through superposition of multiple reverberations from the midcrustal interface. The transverse RF signals within the first $3 \mathrm{~s}$ do not exhibit phases coherent ranges of backazimuths broad enough to warrant modeling. A strongly anisotropic layer above the crust-mantle boundary generates the large two-sided pulse on the transverse component at 3-6 s, while a weaker pulse at $6-8 \mathrm{~s}$ may be satisfied with upcoming conversions from an anisotropic layer between 48- and 62-km depth characterized by a mild velocity inversion. To satisfy the apparent reversal in polarity of the observed two-sided pulse, a slow anisotropy axis within the lower-crustal layer has $\varphi=50^{\circ}$. It is tilted $45^{\circ}$ to reproduce polarity of the observed phase in broad ranges of backazimuths. Orientation of the symmetry axis in the deeper anisotropic layer is chosen to be the same. The fast anisotropic axis reverses the polarity (negative-positive) of the twosided $P s$ pulse. Synthetic radial RFs contain phases beyond $12 \mathrm{~s}$ which arise through constructive interference of multiply reflected waves. Their absence in the observed data is likely due to scattering/defocus-

Fig. 3. (a) Receiver functions for station APA. Two frames on the left show backazimuthal gathers of RFs, for radial and transverse components, respectively. A thick solid line in the transverse RF frame denotes the backazimuthal range used for the epicentral sweep. Two frames on the right denote the epicentral gathers of RFs, for radial and transverse components, respectively. (b) Results of forward modeling for station APA. In waveform plots thick line shows data and thin line shows synthetics. On the lower diagram the change of $V_{\mathrm{S}}$ with depth is shown by a solid line. Variation in peak-to-peak $V_{\mathrm{S}}$ anisotropy is shown by a dashed line. See Table 1 for specific model values. 
Table 1

Parameters of velocity models obtained through forward modeling

\begin{tabular}{llllllll}
\hline $\begin{array}{l}\text { Depth } \\
(\mathrm{km})\end{array}$ & $\begin{array}{l}V_{\mathrm{P}}, \\
\mathrm{km} / \mathrm{s}\end{array}$ & $\begin{array}{l}\mathrm{B}, \% \\
\text { of } V_{\mathrm{P}}\end{array}$ & $\begin{array}{l}V_{\mathrm{S}}, \\
\mathrm{km} / \mathrm{s}\end{array}$ & $\begin{array}{l}\mathrm{E}, \% \\
\text { of } V_{\mathrm{S}}\end{array}$ & $\begin{array}{l}\rho, \\
\mathrm{g} / \mathrm{cm}^{3}\end{array}$ & $\begin{array}{l}\theta, \\
\mathrm{deg}\end{array}$ & $\begin{array}{l}\varphi, \\
\mathrm{deg}\end{array}$ \\
\hline$A P A$ & & & & & & & \\
1.8 & 4.325 & - & 2.5 & - & 2.2 & - & - \\
15.0 & 5.775 & - & 3.3 & - & 2.5 & - & - \\
28.0 & 6.3 & - & 3.6 & - & 2.5 & - & - \\
35.0 & 6.650 & -8 & 3.9 & -8 & 2.7 & 45 & 50 \\
48.0 & 7.7 & - & 4.4 & - & 3.2 & - & - \\
62.0 & 7.7 & 5 & 4.4 & 5 & 3.2 & 45 & 50 \\
$\infty$ & 8.050 & - & 4.6 & - & 3.3 & - & -
\end{tabular}

ESS

2.5

15.0

35.0

46.0

68.0

$\infty$

KRO

2.0

13.0

30.0

33.0

48.0

59.0

$\infty$

MIL

\begin{tabular}{llllllll}
1.750 & 2.7 & - & 1.5 & - & 2.2 & - & - \\
13.5 & 5.950 & - & 3.4 & - & 2.5 & - & - \\
38.0 & 6.3 & - & 3.6 & - & 2.7 & - & - \\
50.0 & 7.7 & 10 & 4.4 & 10 & 2.7 & 130 & 100 \\
67.0 & 8.050 & 5 & 4.6 & 5 & 2.7 & 50 & 100 \\
$\infty$ & 8.050 & - & 4.6 & - & 3.2 & - & - \\
& & & & & & & \\
OSO & & & & & & & \\
2.0 & 5.250 & -15 & 3.0 & -15 & 2.3 & 45 & 300 \\
19.0 & 5.775 & 0.0 & 3.3 & 0.0 & 2.3 & - & - \\
35.0 & 6.300 & 0.00 & 3.6 & 0.00 & 2.7 & - & - \\
42.0 & 6.650 & -4 & 3.6 & -4 & 2.7 & 50 & 130 \\
48.0 & 7.175 & 7 & 4.1 & 7 & 2.7 & 50 & 310 \\
55.0 & 8.050 & 3 & 4.6 & 3 & 3.3 & 50 & 310 \\
$\infty$ & 8.050 & - & 4.6 & - & 3.3 & - & - \\
& & & & & & & \\
$P A N$ SE/NW & & & & & & & \\
$21.0 / 11.0$ & 5.450 & - & 3.1 & - & 2.3 & - & - \\
25.0 & 6.125 & - & 3.5 & - & 2.5 & - & - \\
31.0 & 6.125 & $5 / 7$ & 3.5 & $5 / 7$ & 2.5 & $70 / 40$ & 80 \\
$36.0 / 39.0$ & 8.050 & 7 & 4.6 & 7 & 3.1 & $70 / 40$ & 80 \\
$61.0 / 60.0$ & 8.050 & 7 & 4.6 & 7 & 3.1 & $70 / 40$ & 250 \\
$\infty$ & 8.050 & - & 4.6 & - & 3.3 & - & - \\
\hline
\end{tabular}

Table 1 (continued)

\begin{tabular}{|c|c|c|c|c|c|c|c|}
\hline $\begin{array}{l}\text { Depth } \\
(\mathrm{km})\end{array}$ & $\begin{array}{l}V_{\mathrm{P}} \\
\mathrm{km} / \mathrm{s}\end{array}$ & $\begin{array}{l}\mathrm{B}, \% \\
\text { of } V_{\mathrm{P}}\end{array}$ & $\begin{array}{l}V_{\mathrm{S}}, \\
\mathrm{km} / \mathrm{s}\end{array}$ & $\begin{array}{l}\mathrm{E}, \% \\
\text { of } V_{\mathrm{S}}\end{array}$ & $\begin{array}{l}\rho, \\
\mathrm{g} / \mathrm{cm}^{3}\end{array}$ & $\begin{array}{l}\theta, \\
\text { deg }\end{array}$ & $\begin{array}{l}\varphi, \\
\text { deg }\end{array}$ \\
\hline \multicolumn{8}{|l|}{$T I G$} \\
\hline 1.0 & 3.7 & 0 & 2.1 & - & 2.0 & - & - \\
\hline 6.0 & 5.6 & - & 3.2 & - & 2.3 & - & - \\
\hline 10.0 & 5.6 & -5 & 3.2 & -5 & 2.3 & 50 & 340 \\
\hline 13.0 & 5.6 & - & 3.2 & - & 2.4 & - & - \\
\hline 25.0 & 6.3 & - & 3.6 & - & 2.5 & - & - \\
\hline 32.0 & 6.3 & -7 & 3.6 & -7 & 2.8 & $60 / 60$ & $\begin{array}{l}290 / \\
110\end{array}$ \\
\hline 47.0 & 8.050 & - & 4.6 & - & 3.1 & - & - \\
\hline 5.7 & 8.050 & 5 & 4.6 & 5 & 3.1 & 50 & 350 \\
\hline$\infty$ & 8.050 & - & 4.6 & - & 3.1 & - & - \\
\hline \multicolumn{8}{|l|}{$T U M$} \\
\hline 2.5 & 4.4 & - & 2.5 & - & 2.2 & - & - \\
\hline 10.0 & 5.250 & -10 & 3.0 & -10 & 2.5 & 130 & 130 \\
\hline 14.5 & 5.250 & - & 3.0 & - & 2.5 & 130 & 130 \\
\hline 31.0 & 6.125 & - & 3.5 & - & 2.7 & - & - \\
\hline 38.0 & 8.050 & - & 4.6 & - & 3.0 & - & - \\
\hline 65.0 & 8.050 & 5 & 4.6 & 5 & 3.0 & 130 & 130 \\
\hline$\infty$ & 8.050 & - & 4.6 & - & 3.3 & - & 0 \\
\hline \multicolumn{8}{|l|}{$U H R$} \\
\hline 2.0 & 3.0 & - & 1.7 & - & 2.0 & - & - \\
\hline 9.0 & 4.9 & - & 2.8 & - & 2.3 & - & - \\
\hline 21.0 & 6.125 & -9 & 3.5 & -9 & 2.5 & 50 & 315 \\
\hline 38.0 & 6.825 & - & 3.9 & - & 2.8 & - & - \\
\hline 42.0 & 8.400 & - & 4.8 & - & 3.1 & - & - \\
\hline 55.0 & 8.050 & 7 & 4.6 & 7 & 3.1 & 50 & 200 \\
\hline$\infty$ & 8.050 & - & 4.6 & - & 3.3 & - & - \\
\hline
\end{tabular}

Depth indicates the bottom of each layer. The anisotropy coefficients $B$ and $E$ scale peak-to-peak variations of $V_{\mathrm{P}}$ and $V_{\mathrm{S}}$, respectively, each with $\cos 2 \eta$ azimuthal dependence (Park, 1996). The angles $\theta$ and $\varphi$ define the inclination (from vertical) and the strike (CW from north) of the axis of symmetry within each anisotropic layer. For two stations, PAN and TIG, two structures are presented, representative of different backazimuthal ranges.

ing effects of small-scale structures not accounted for by the model.

\subsection{2. $M I L$}

Station MIL recorded reliable data primarily from the south (Fig. 4a). Few RFs in backazimuthal range $270^{\circ}-330^{\circ}$ appear to be dominated by scattering effects, as they are not coherent. In backazimuthal range $170^{\circ}-240^{\circ}$, the peak of the initial radial pulse is delayed by $0.5 \mathrm{~s}$ or more. A prominent negative swing at $2.5 \mathrm{~s}$ is followed by a broad positive pulse 
(a)

MIL

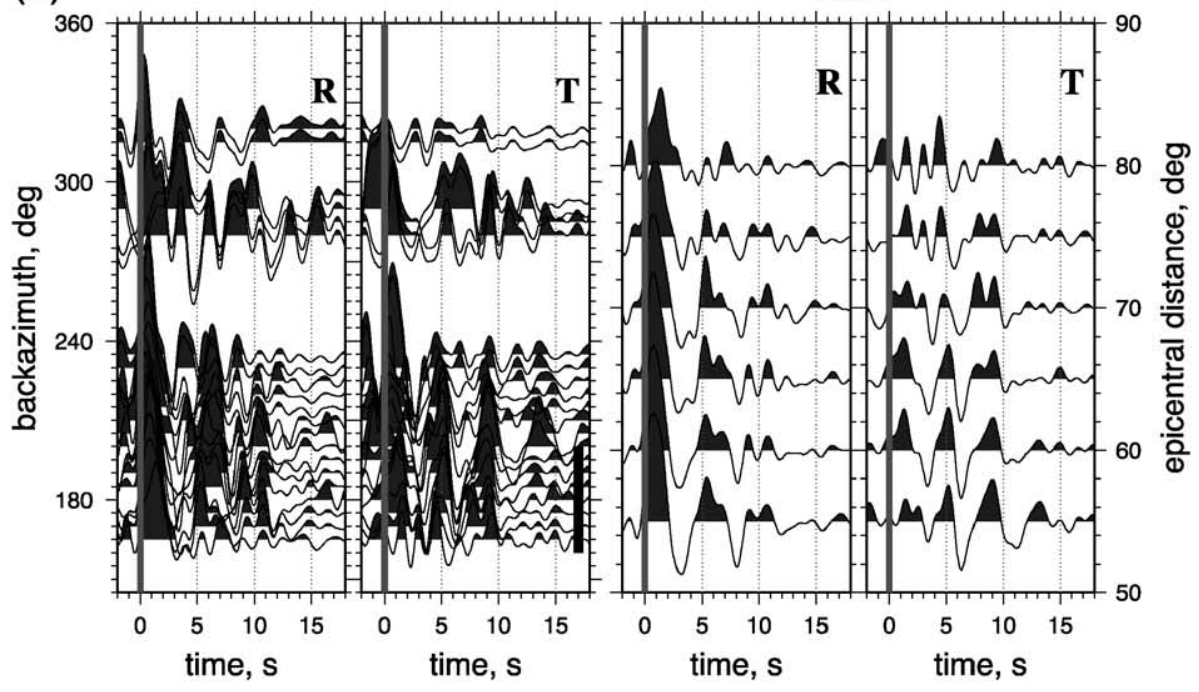

(b)
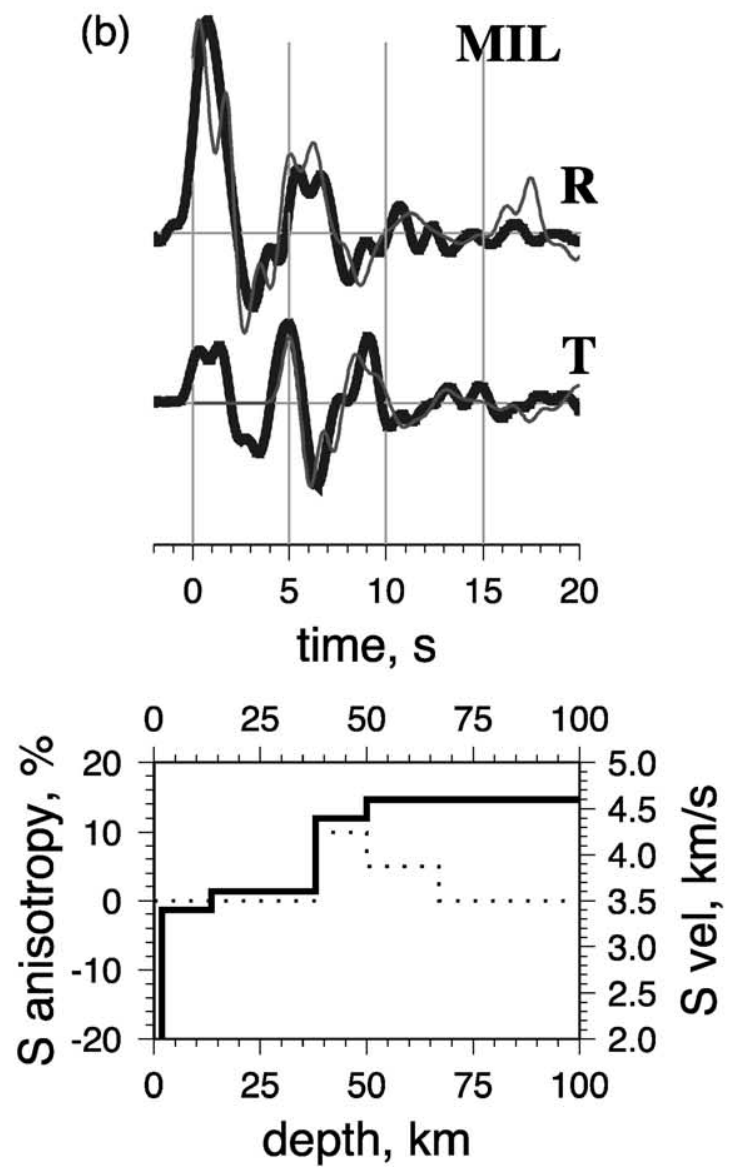

Fig. 4. (a) Same as Fig. 3a for station MIL. (b) Same as Fig. 3b for station MIL. 
between 4 and 7 s. In some directions, this pulse shows evidence of being composed of at least two closely spaced positive pulses. Transverse RFs show a sequence of three positive pulses - at near-0 lag, at $5 \mathrm{~s}$ and between 9 and $10 \mathrm{~s}$, and similarly prominent negative pulses at 3 and $8 \mathrm{~s}$. Most RF features exhibit little moveout with epicentral distance, and those that do, arrive earlier with increased source distance.

Much of the RF behavior may be satisfied with two features of the velocity model (Fig. 4b, Table 1): a thin very low velocity near-surface layer and a strongly anisotropic layer below the base of the crust. The anisotropy has a fast symmetry axis with $\varphi=280^{\circ}$

(a) ESS

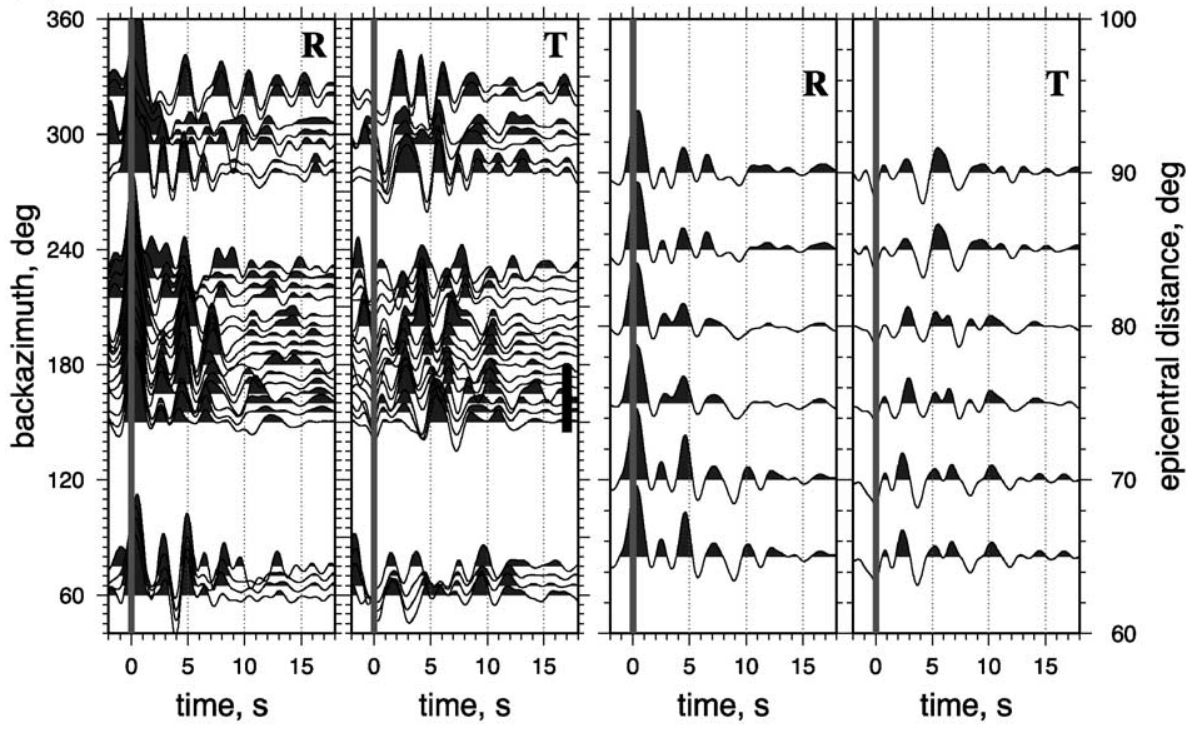

(b)

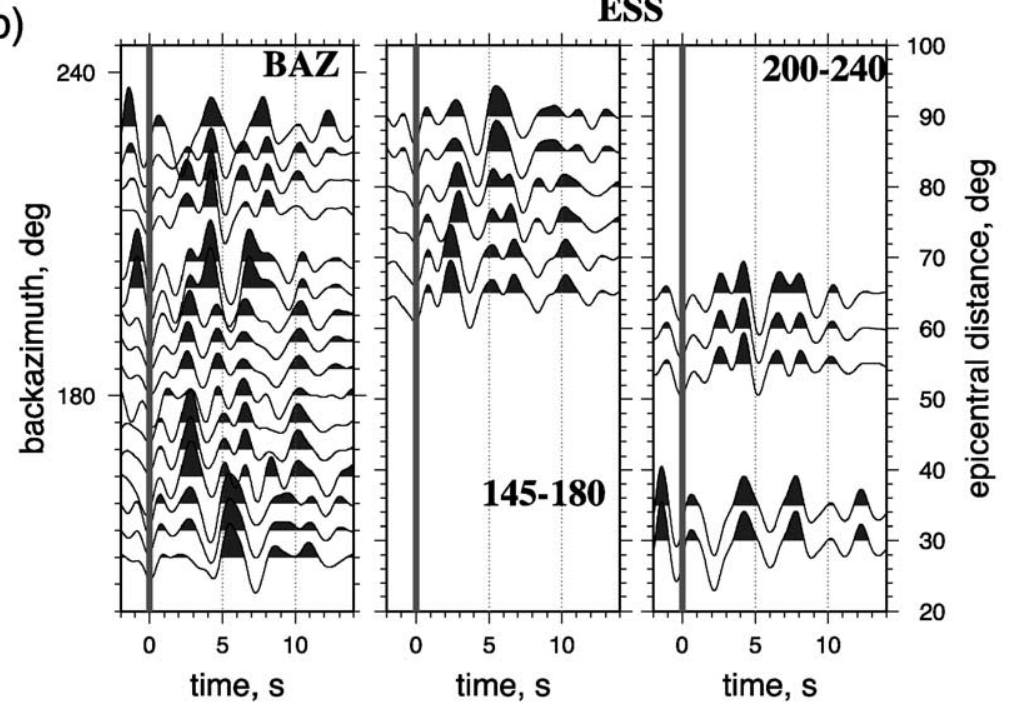

Fig. 5. (a) Same as Fig. 3a for station ESS. (b) Transverse receiver functions in backazimuthal range $140^{\circ}-240^{\circ}$. A clear reversal in polarity of the phase at $5 \mathrm{~s}$ is seen between eastern and western parts of the backazimuthal sector. (c) Same as Fig. $3 \mathrm{~b}$ for station ESS. 
(c)
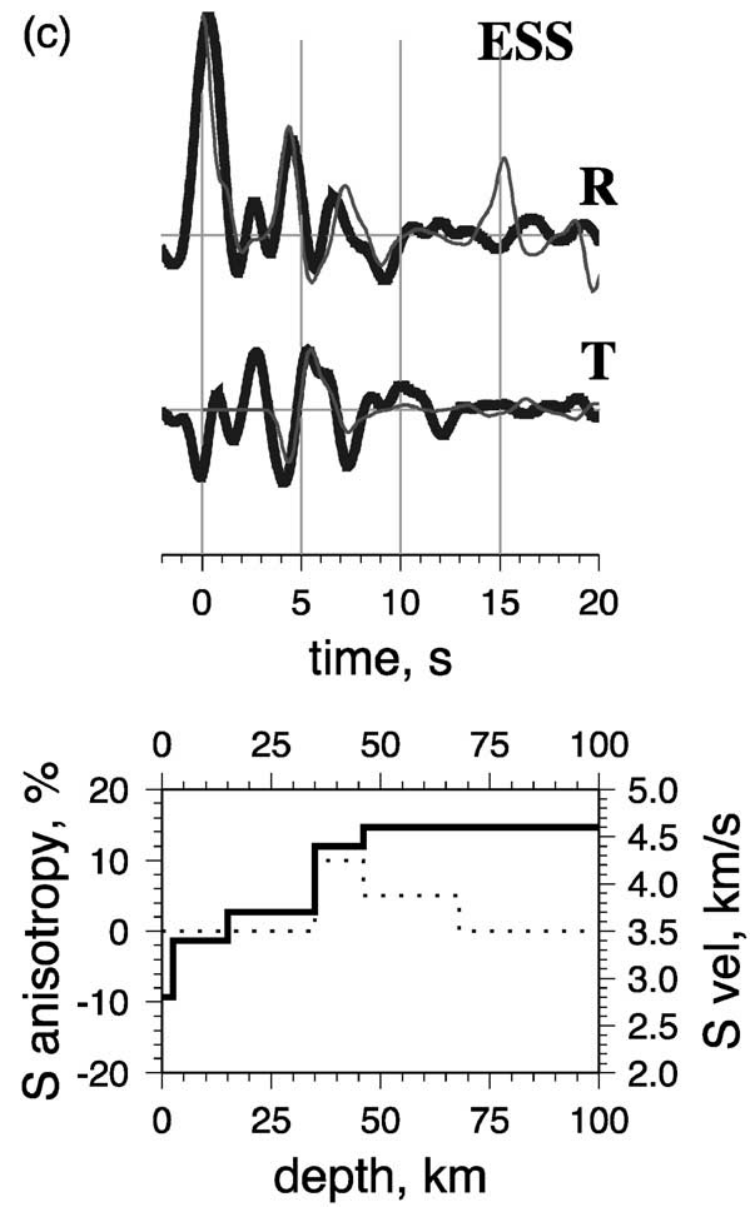

Fig. 5 (continued).

and $\theta=50^{\circ}$. It extends from the crust - mantle transition at $38 \mathrm{~km}$ to a depth of $50 \mathrm{~km}$. Shallow resonances account for the delay and broadening of the initial radial pulse, the negative swing at $2.5 \mathrm{~s}$ and the leading part of the positive pulse at $4 \mathrm{~s}$ on the radial component. They also contribute most of the energy to the transverse synthetic waveform between 4 and $10 \mathrm{~s}$. The later part of the radial pulse (between 4 and $7 \mathrm{~s}$ ) and a weak broad negative pulse behind it are well matched by multiply reflected phases from the velocity increase in the upper crust. The transverse phase between 8 and $10 \mathrm{~s}$ is matched by conversions formed at the boundaries of the second anisotropic layer in the mantle, between 50 and $67 \mathrm{~km}$. The azimuth of its fast symmetry axis is chosen to be the same as in the layer above, with an opposite inclination to reverse the polarity of the converted phase. Initial motion on the transverse component is not modeled. The observed effect (a strong positive pulse followed by a broader negative) can result from $\sim 10 \%$ anisotropy in the near-surface layer, but may also be caused by a dip of the bottom of this layer. Given the strength of the velocity contrast, a dip of $\sim 10^{\circ}$ will deflect enough energy within the first-arriving $P$ wave onto the transverse component.

\subsubsection{ESS}

The RFs obtained for station ESS are shown in Fig. 5a. Data of sufficient quality were received from all three main source regions. A clear positive radial phase arrives at $4.5 \mathrm{~s}$ from all directions. In backazimuthal range $145^{\circ}-210^{\circ}$, it is followed by another positive pulse, arriving between 6 and $7 \mathrm{~s}$. An earlier positive phase, at $2.5-3 \mathrm{~s}$, is seen intermittently in a number of narrow backazimuth ranges. On the transverse component, a two-sided phase arrives between 4 and $6 \mathrm{~s}$. It displays a clear reversal of polarity (Fig. 5b) between backazimuthal ranges $145^{\circ}-180^{\circ}$ (negative-positive) and $200^{\circ}-240^{\circ}$ (positive-negative). An additional lobe is seen at the tail of this phase in narrow ranges of backazimuths (negative around $165^{\circ}$ and positive around $230^{\circ}$ ). Also, between backazimuths $160^{\circ}$ and $210^{\circ}$, weaker transverse positive pulses arrive at 3 and $10 \mathrm{~s}$.

Similar to station MIL, the majority of the RF features are explained by a velocity model (Fig. 5c, Table 1) that contains a shallow layer of relatively low velocity on top, and a strongly anisotropic layer below the base of the crust, which is at $35 \mathrm{~km}$ in the ESS model. A clearly observed polarity reversal constrains the axis of symmetry to have $\varphi=20^{\circ}$. An inclined $\left(\theta=50^{\circ}\right)$ axis is used to account for the strength of the transverse signal. These model features produce a broadened initial pulse on the radial component, the positive radial pulse at $4.5 \mathrm{~s}$, and the bulk of the transverse energy between 3 and 7 s. A velocity increase at $15 \mathrm{~km}$ produces multiple reflections that arrive at 6.5 and $9 \mathrm{~s}$ (positive and negative polarity, respectively). The transverse phase observed between 7 and $8 \mathrm{~s}$ is matched with conversions from the second anisotropic layer in the mantle, between 46 and 68 $\mathrm{km}$. The azimuth of its fast symmetry axis is chosen to be the same as in the layer above, with an opposite inclination to reverse the polarity of the converted 
phase. In simulations from the southwestern direction (not shown) this later phase is not generated, matching the observed backazimuthal behavior of transverse RFs.

\subsubsection{TUM}

Observations from south, northeast and west-northwest were acquired at TUM (Fig. 6a). The RFs are fairly complicated, and characterized by a high level of signal. The radial component shows a coherent positive pulse at $4 \mathrm{~s}$ from most directions, followed by two or more positive pulses. In backazimuthal range $160^{\circ}-210^{\circ}$, two coherent pulses arrive at 7.5 and 10 s. On the transverse component, a prominent twosided pulse dominates the initial $2 \mathrm{~s}$ of the trace. In backazimuth range $160^{\circ}-210^{\circ}$, the leading swing is negative, while arrivals from the east show a positive leading swing, and an extra lobe at $2.5 \mathrm{~s}$. Transverse RFs also show a weaker broad two-sided pulse between $4.5-5$ and $7.5 \mathrm{~s}$. Another positive pulse arrives at $11-12 \mathrm{~s}$, and exhibits a noticeable change in timing as a function of backazimuth.

In modeling RF behavior at TUM, we had only modest success in reproducing all features of the radial component. A velocity change from crustal to mantle values at $31 \mathrm{~km}$ generates a positive pulse at $4 \mathrm{~s}$. Judging by their relative intensity, oscillations at later times reflect multiple reverberations within near-surface layers. One such reverberation, from a velocity increase at $14.5 \mathrm{~km}$, would fit a pronounced positive pulse at $7.5 \mathrm{~s}$. Matching the entire pattern would require analysis of high-frequency data from closer events, which is beyond the scope of this study. Modeling the behavior of the transverse component, we find that a strongly $(10 \%)$ anisotropic layer in the shallow subsurface (Fig. 6b, Table 1) would produce the desired effect. The axis of symmetry has parameters $\varphi=320$, $\theta=50$ to accommodate the similarity of pulse shapes seen from the south and the northwest, and the reversed pulse shape from the east. A slow axis is postulated as this is a more likely scenario in the upper crust. The size and two-sided nature of this large transverse pulse suggest that anisotropy plays a significant role in its generation. However, here we cannot rule out the dip of the velocity interface with respect to the horizontal as a possible cause of the observed signal. Transverse energy arriving between 4.5 and $7.5 \mathrm{~s}$ is matched well by mode-converted phases from the top and the bottom of an anisotropic layer in the mantle, between 38 and $65 \mathrm{~km}$. A broad range of symmetry-axis azimuths $\left(270^{\circ}-300^{\circ}\right)$ would produce the desirable effect, with $\theta \sim 50^{\circ}$.

\subsection{Western coast}

Stations on the western coast were located within settlements. Cultural noise levels were higher here. However, this group of stations operated until early September of 1999, and recorded a number of highquality events that occurred towards the end of the deployment.

\subsection{1. $U H R$}

Data were collected primarily from the southern, eastern and northwestern source regions (Fig. 7a), providing illumination in narrow backazimuthal ranges. Radial component data contain three positive pulses clustered closely between 0 and $3 \mathrm{~s}$, and another positive pulse at $5 \mathrm{~s}$. A broad negative swing arrives between 6 and $8 \mathrm{~s}$ in backazimuthal range $150^{\circ}-190^{\circ}$. On the transverse component, two positive pulses are seen at 3.5 and $5.5 \mathrm{~s}$ for the southern arrivals, while arrivals from the east show a sequence of two negative pulses at 3.5 and $5 \mathrm{~s}$.

The model (Fig. 7b, Table 1) constructed for the UHR data set captures the behavior of the radial RFs with considerable fidelity. A transition from crustal to mantle velocities at $38 \mathrm{~km}$ creates a positive radial pulse at $5 \mathrm{~s}$. The surface layer with very low velocity, and two velocity increases, at 9 and $21 \mathrm{~km}$, set up the system of positive pulses within the initial $3 \mathrm{~s}$ of the radial RF, and also contribute to the broad negative pulse at $7 \mathrm{~s}$. Anisotropy within the mid-crustal layer $(9-21 \mathrm{~km})$ has a slow symmetry axis with $\varphi=315^{\circ}$, $\theta=50^{\circ}$, and is responsible for the two-sided transverse pulse between 1.7 and $3.5 \mathrm{~s}$. Anisotropy with a fast symmetry axis and similar orientation $\left(\varphi=300^{\circ}\right.$, $\theta=40^{\circ}$ ), between 42 and $55 \mathrm{~km}$, yields a two-sided pulse between 5.5 and $7 \mathrm{~s}$. A thin isotropic highvelocity layer immediately below the crust achieves a temporal offset between the radial phase at $5 \mathrm{~s}$ and the positive swing on the transverse at $5.5 \mathrm{~s}$, and also contributes to the intensity of positive and negative radial pulses between 5 and $7 \mathrm{~s}$. 
(a) TUM

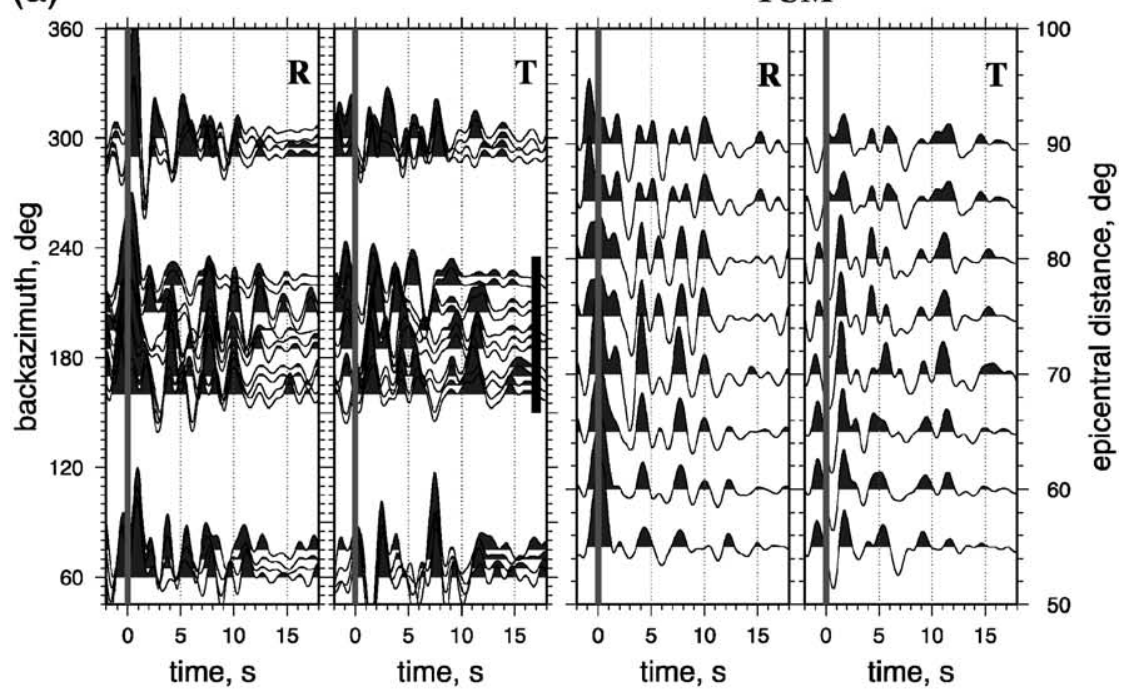

(b)
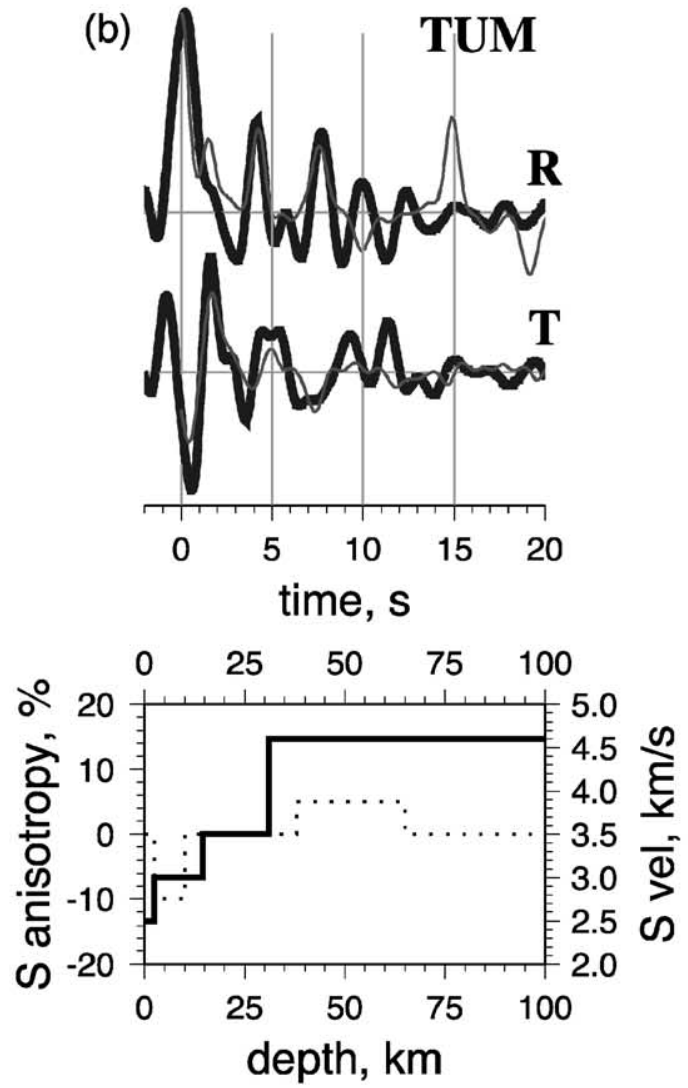

Fig. 6. (a) Same as Fig. 3a for station TUM. (b) Same as Fig. 3b for station TUM. 
(a)

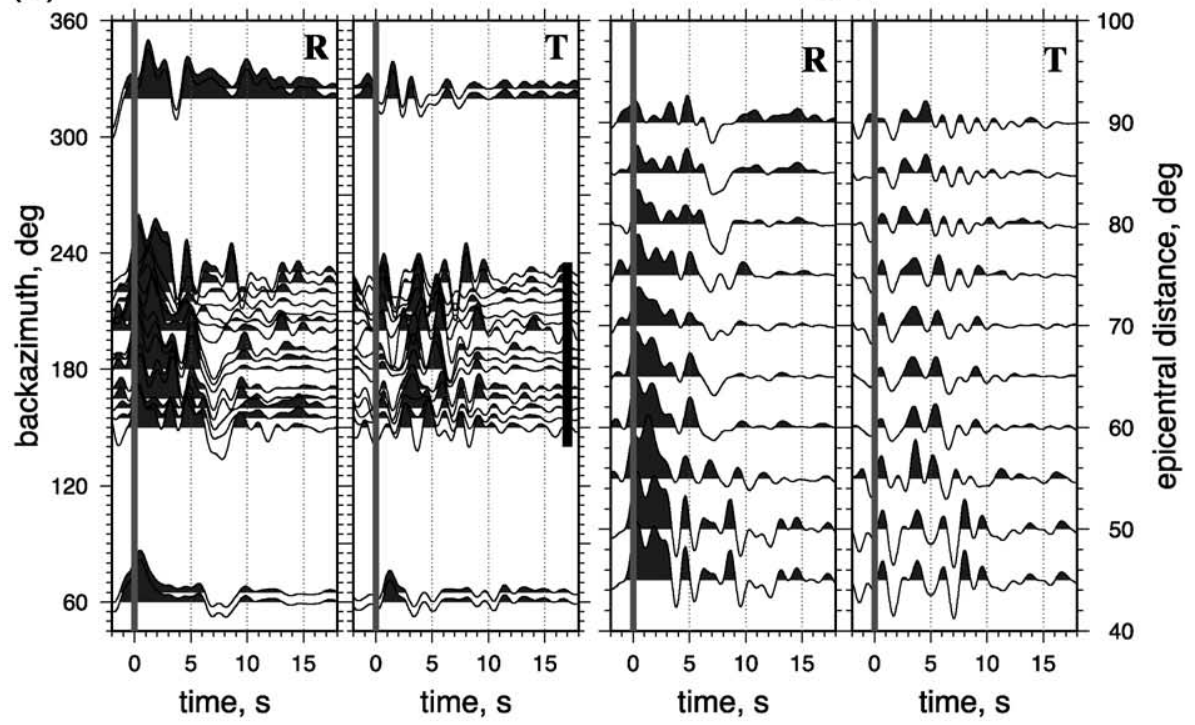

(b)
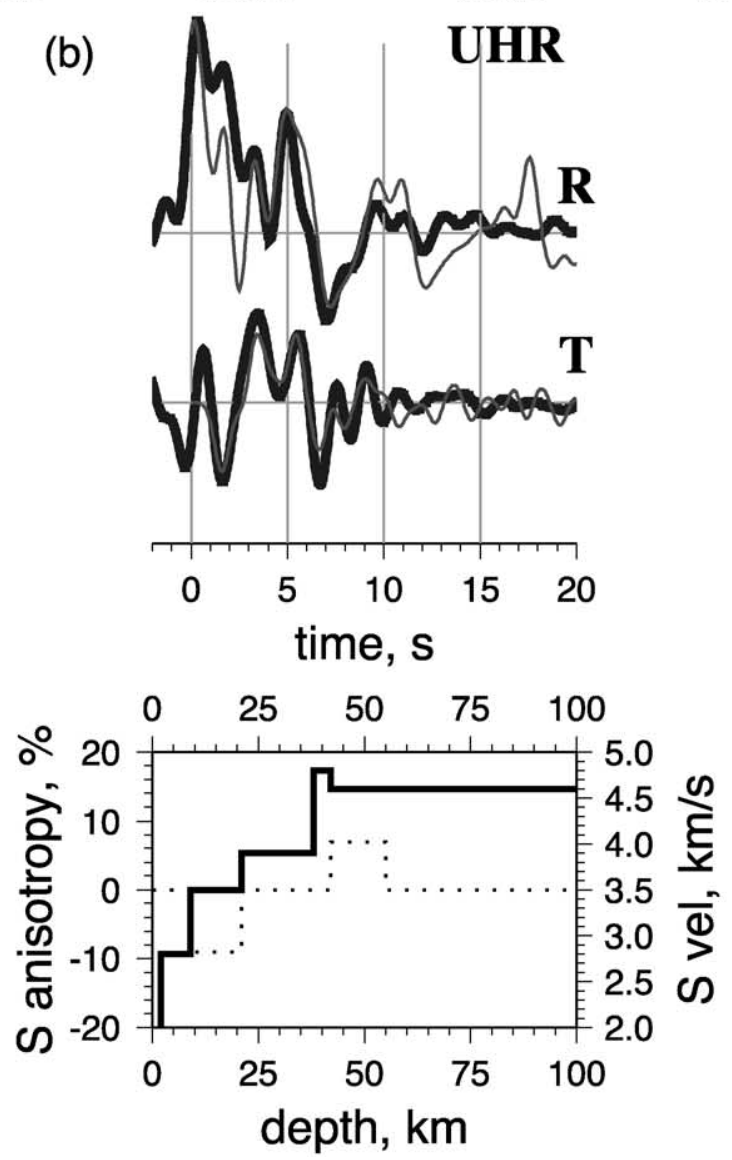

Fig. 7. (a) Same as Fig. 3a for station UHR. (b) Same as Fig. 3b for station UHR. 


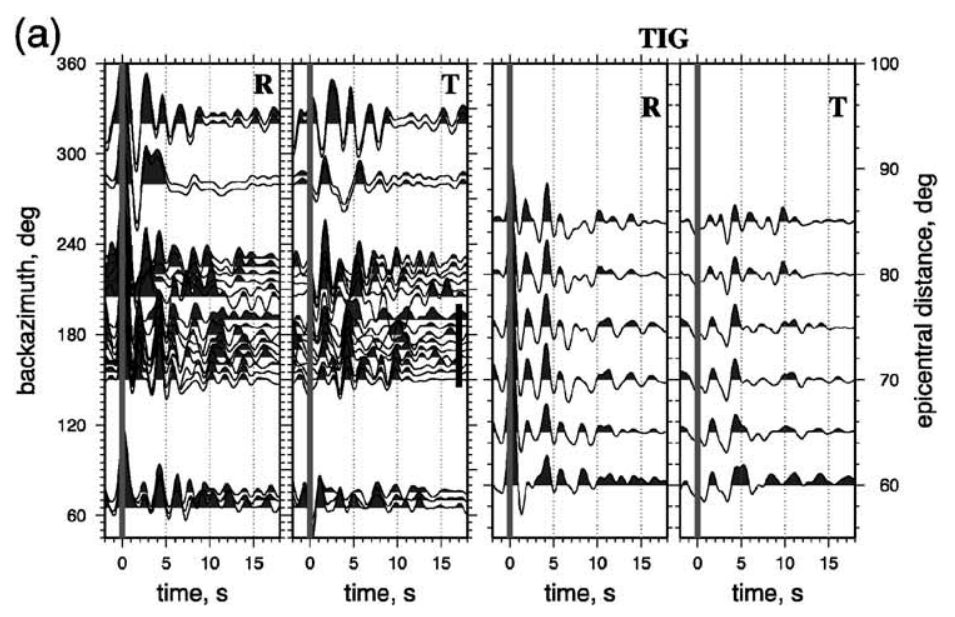

(b)
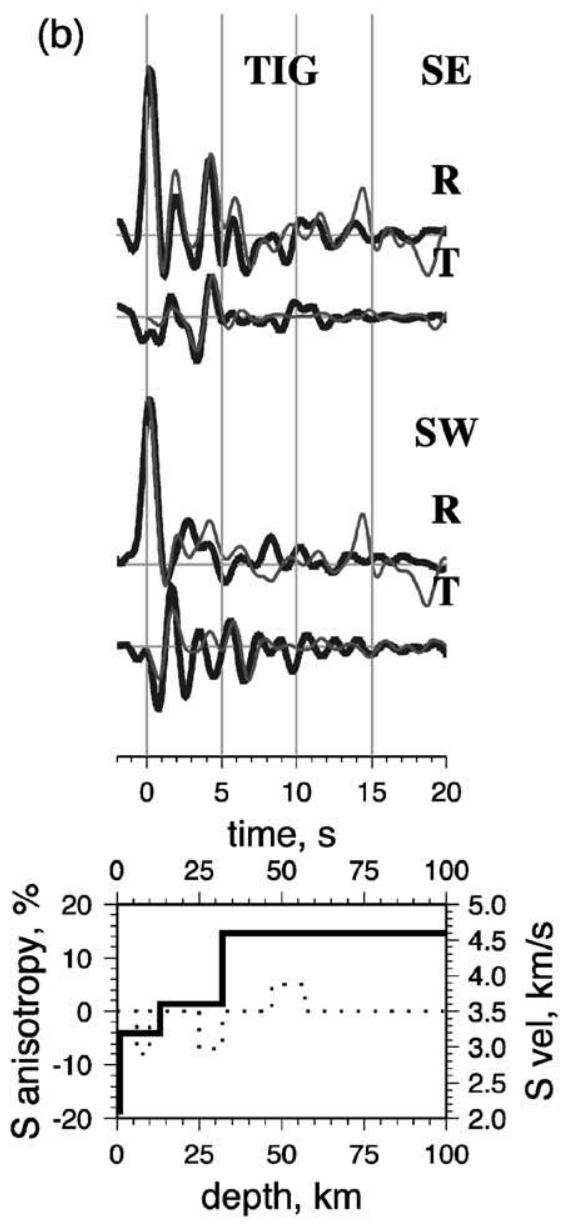

Fig. 8. (a) Same as Fig. 3a for station TIG. (b) Same as Fig. 3b for station TIG. 


\subsection{2. $T I G$}

Data observed at station TIG (Fig. 8a) yielded usable RFs primarily from the south. On the radial component, strong coherent positive pulses are seen at 2 and $4 \mathrm{~s}$, and negative pulses of nearly equal strength arrive at 1.5 and $3 \mathrm{~s}$. A weaker positive pulse also arrives at $5.5-6 \mathrm{~s}$ in backazimuthal range $140^{\circ}-200^{\circ}$.
A two-sided radial pulse is seen between 9 and $11 \mathrm{~s}$ in backazimuthal range $140^{\circ}-180^{\circ}$. On the transverse component a positive pulse is seen at $1.5-2 \mathrm{~s}$, its strength increasing from southeast to southwest. Also, in the backazimuthal range $200^{\circ}-240^{\circ}$, this pulse is preceded and followed by negative pulses. A multicycle phase is observed on the transverse component

(a)

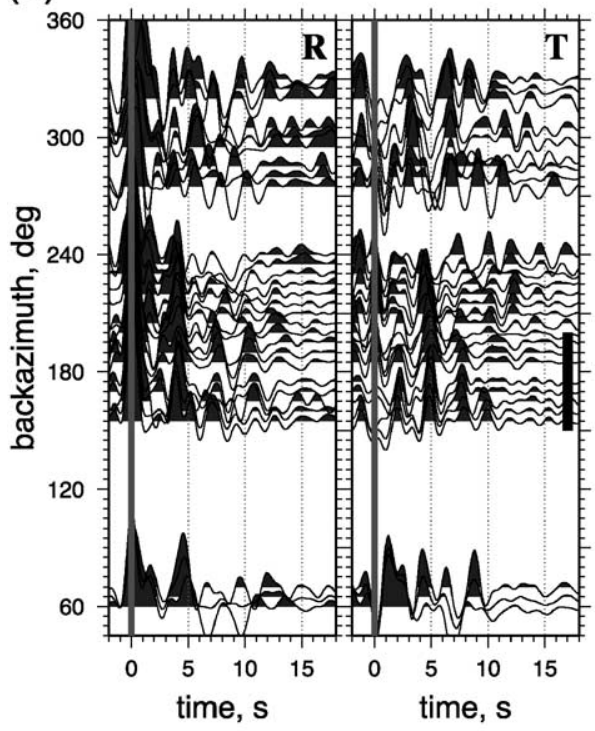

(b)
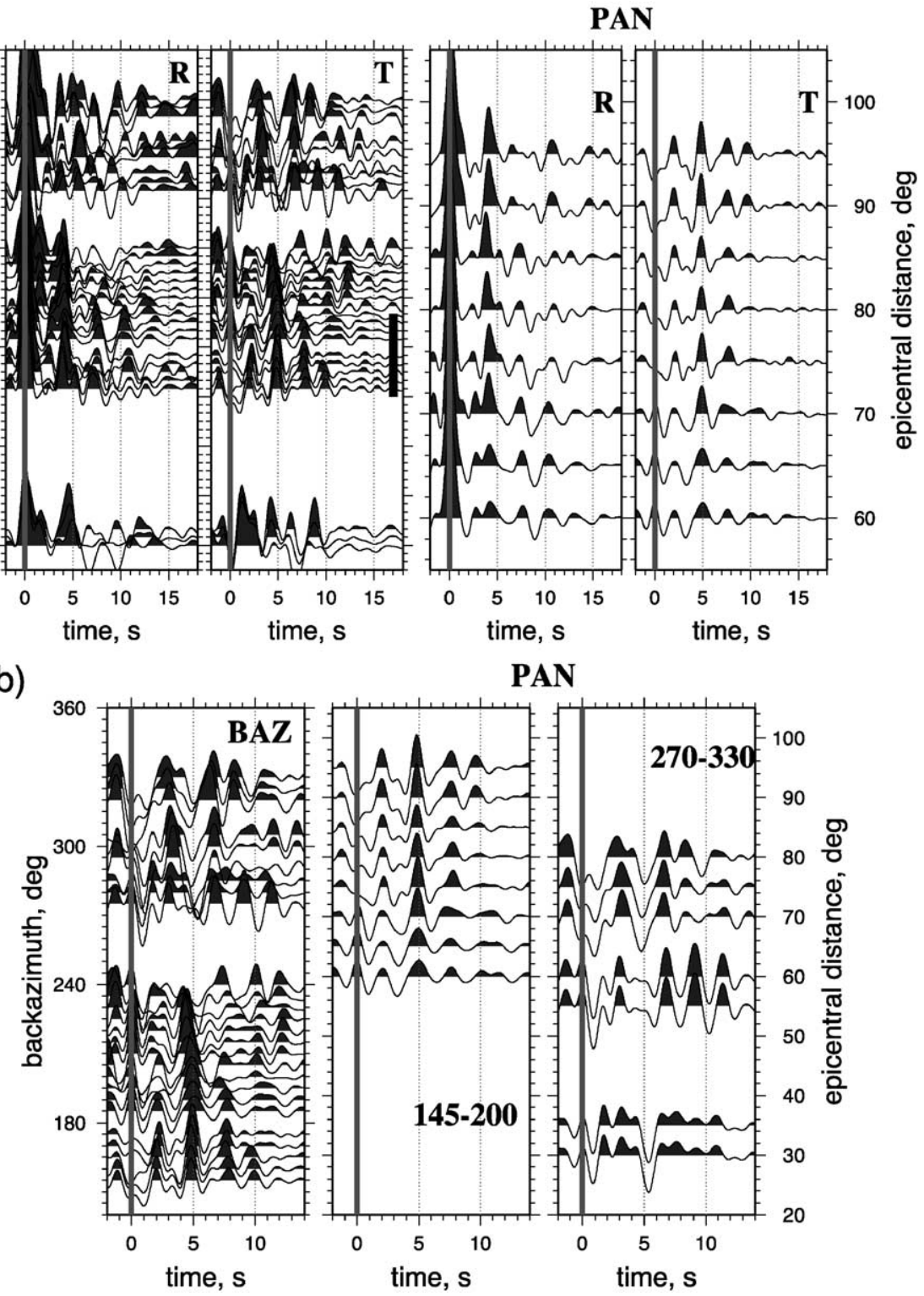

Fig. 9. (a) Same as Fig. 3b for station PAN. (b) Transverse receiver functions in backazimuthal range $140^{\circ}-360^{\circ}$. A clear reversal in polarity of the phase at $5 \mathrm{~s}$ is seen between southers and northwestern parts of the backazimuthal sector. (c) Same as Fig. $3 \mathrm{~b}$ for station PAN. 
(c)
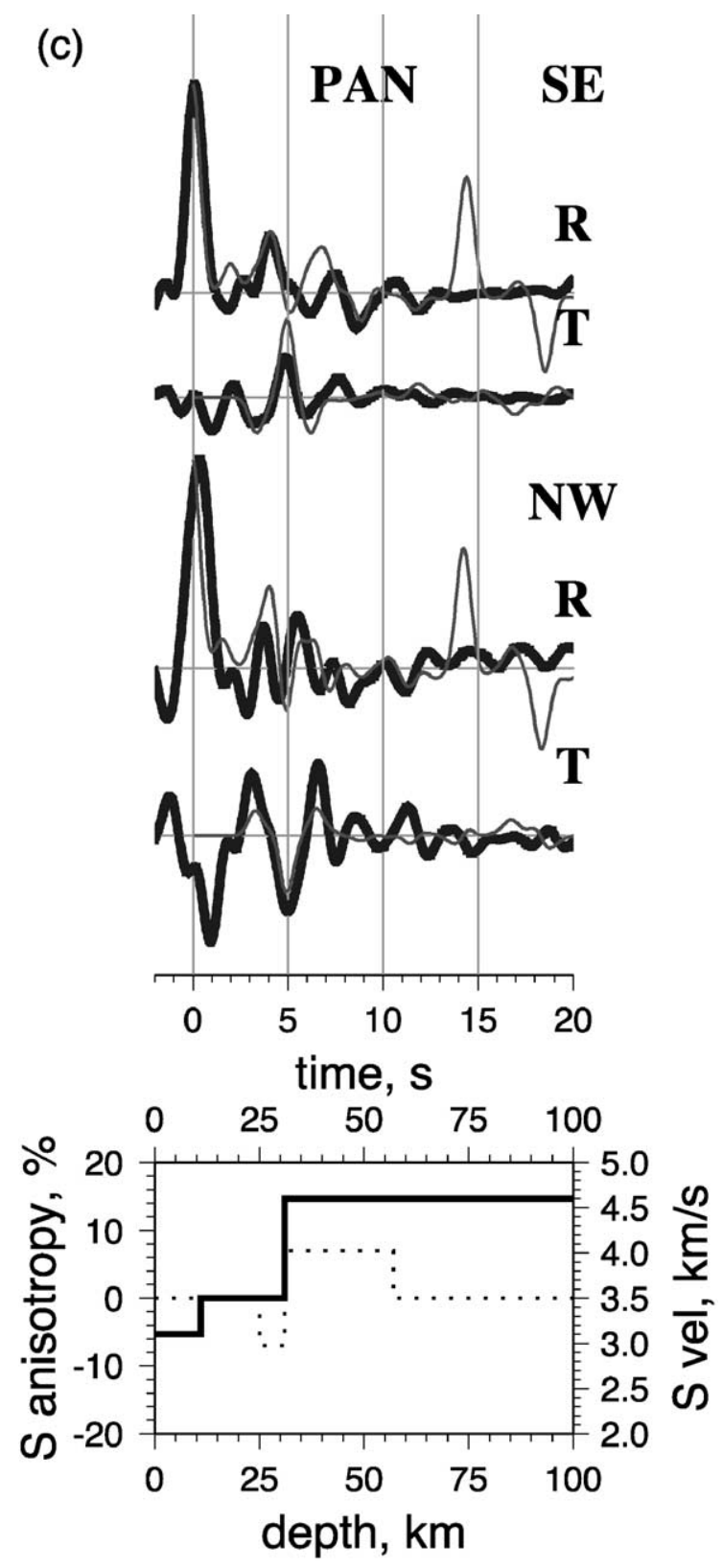

Fig. 9 (continued).

between 3.5 and $6 \mathrm{~s}$. Timing of the positive swing within this phase appears to evolve with backazimuth, with a cumulative moveout of almost $2 \mathrm{~s}$ between backazimuths $150^{\circ}$ and $235^{\circ}$. A two-sided phase arrives on the transverse around $10 \mathrm{~s}$ between backazimuths $140^{\circ}$ and $180^{\circ}$.
Developing the velocity model for TIG, we explored the possibility that transverse energy between 3.5 and $6 \mathrm{~s}$ is generated by an inclined feature in the subsurface. We find that the moveout with backazimuth is too large to be accounted for with a dipping interface, even if we posit structures with dips exceeding $60^{\circ}$. Another argument against dipping features is the absence of corresponding radial signals. A more likely explanation is that the transverse pulse is formed by a combination of two backazimuth-dependent pulses, characteristic of anisotropic layers. Fig. 8b shows synthetic seismograms computed for the same model (Table 1) for azimuths $170^{\circ}$ and $235^{\circ}$. An anisotropic layer at the base of the crust generates the two-sided pulse between 3.5 and $4.3 \mathrm{~s}$ in the southeast synthetic. In the southwest synthetic, the upper-crustal anisotropic layer makes a large twosided pulse between 0.7 and $2 \mathrm{~s}$, while a layer of weak anisotropy in the upper mantle $(47-57 \mathrm{~km})$ yields a two-sided pulse between 5.5 and $7 \mathrm{~s}$. To achieve this combination, upper-crustal and uppermantle anisotropic layers have symmetry axes close to the north-south direction, while the lower-crustal layer has an anisotropic axis with $\varphi=290^{\circ}$. On the radial component, the positive phase at $4 \mathrm{~s}$ is produced by the crust-mantle transition at $32 \mathrm{~km}$, while other positive and negative pulses are formed by reverberations from the near-surface low-velocity layer and the velocity increase at $13 \mathrm{~km}$. Modeling exercise for TIG illustrates the influence of anisotropy on the radial component of RFs: the southeastern synthetic shows a sequence of well defined pulses, while the southwestern one is much more diffuse, similar to the observations.

\subsubsection{PAN}

Station PAN received ample data from the southern and west-northwestern quadrants (Fig. 9a). The RFs are comparatively simple. On the radial component, a positive pulse arrives at $4 \mathrm{~s}$ from all directions, although it is seen best from the south. In backazimuthal range $180^{\circ}-200^{\circ}$, a sequence of two positive pulses separated by a broad negative is seen between 7.5 and $11 \mathrm{~s}$. On the transverse component, a positive pulse at $5 \mathrm{~s}$ is preceded and followed by negative pulses in backazimuthal range $165^{\circ}-240^{\circ}$. This sequence is seen with reversed polarity in backazimuthal range $275^{\circ}-335^{\circ}$ (Fig. 9b). 
The model for PAN (Fig. 9c, Table 1) contains only two major velocity interfaces, in the upper crust and at the crust-mantle transition, but provides a reasonable fit to the radial RFs for southern and northwestern backazimuthal ranges. The positive pulse at $4 \mathrm{~s}$ is generated at the crust-mantle transition at $31 \mathrm{~km}$. The velocity change at $14 \mathrm{~km}$ contributes multiply reflected energy seen between 5 and $10 \mathrm{~s}$ from the south. Reducing the depth of this interface to $11 \mathrm{~km}$ (with no change in velocity) produces a waveform that satisfies the northwestern radial RF gather. Large multiply reflected phases at 15 and $20 \mathrm{~s}$ are not seen in the data, suggesting that small-scale, potentially three-dimensional heterogeneity is present in the crust.

To match the transverse component, we introduced three layers of anisotropy into the model. Above the crust-mantle transition, we posit anisotropy with a slow symmetry axis $\left(\varphi=250^{\circ}, \theta=40^{\circ}\right)$. Below the transition, we introduce two layers with fast anisotropy axes and similar orientation: $\varphi=80^{\circ}, \theta=40^{\circ}$ in the upper layer, and $\varphi=250^{\circ}, \theta=40^{\circ}$ in the lower layer. In concert, these three layers give rise to a phase that has three swings, positive-negative-positive from the northwest, and reversed from the south. To account for the slight difference in phase duration, the lower layer of anisotropy is $4 \mathrm{~km}$ thicker in the northwestern model.

\subsection{East coast}

Stations along the east coast of Kamchatka were located in a relatively high-noise environment close to the shoreline. Also, station ZUP was affected by the eruptive activity of a nearby Karyimsky volcano, and station OSO was located close to an active road. At station KRO, activity of the caretaker personnel made night hours more favorable for recording undistorted horizontal particle motions.

\subsubsection{OSO}

Due to a combination of frequent power outages and the high level of cultural noise, the data set for OSO is fairly sparse (Fig. 10a). In the southwestern quadrant, a small positive pulse appears on the radial component at $2 \mathrm{~s}$. A larger positive pulse is seen between 5 and $6 \mathrm{~s}$, depending on the direction. On the transverse component, two positive pulses are seen at
0.5 and $4.5 \mathrm{~s}$. The later is followed by a broad negative phase. Only two events contributed to the eastern backazimuthal RF gather, which appear quite different from the southwestern one. The radial RF is dominated by an oscillatory signal, while on the transverse, a double-sided phase is seen between 3 and $5 \mathrm{~s}$.

We developed a model for the southwestern RFs (Fig. 10b, Table 1). A small radial phase at $2 \mathrm{~s}$ is matched well with a multiple bounce from the low velocity layer at the surface. Strong anisotropy in that layer $\left(\varphi=300^{\circ}, \theta=45^{\circ}\right)$ yields a positive transverse phase at $0.5 \mathrm{~s}$. A broad positive radial phase between 4 and $7.5 \mathrm{~s}$ is matched by combined contributions from velocity interfaces at 42 and $48 \mathrm{~km}$. While $42 \mathrm{~km}$ is the lower limit of the nominal crustal velocities, the crust-mantle transition under OSO might be marked by a gradual change in properties taking place over the 30-50 $\mathrm{km}$ depth range. A velocity increase at $19 \mathrm{~km}$ sets up a pattern of multiple reverberations seen on the radial component in the $8-11$-s time window. The transverse phase in the 4-8-s time window is matched well by combined contributions from three layers of anisotropy: a layer with slow anisotropic direction at $\varphi=130^{\circ}, \theta=50^{\circ}$ located between 35 and $42 \mathrm{~km}$, and two fast-axis layers between 42 and $55 \mathrm{~km}$ with a common fast anisotropic direction of $\varphi=310^{\circ}, \theta=50^{\circ}$.

\subsubsection{KRO}

Station KRO received reliable data from eastern and southern source regions (Fig. 11a). For southern RFs, the initial pulse on the radial component is broadened and offset from the origin by up to $1 \mathrm{~s}$. A positive radial phase is seen at $3 \mathrm{~s}$ from the east, and in some subsets of southern RFs. A collection of direction-dependent positive pulses appears on the radial between 5 and $7.5 \mathrm{~s}$, often followed by a broad negative phase that exhibits backazimuth-dependent moveout. A poorly defined positive phase with similar moveout is seen on the radial between 10 and $11 \mathrm{~s}$. The dominant feature of the transverse component is the phase observed between 5 and $8 \mathrm{~s}$. In the southern RF gather it contains three swings (negative-positive-negative), while a reversed-polarity sequence is seen in the eastern RF gather. Additional transverse phases arrive in the 2-4-s time window, and also at 

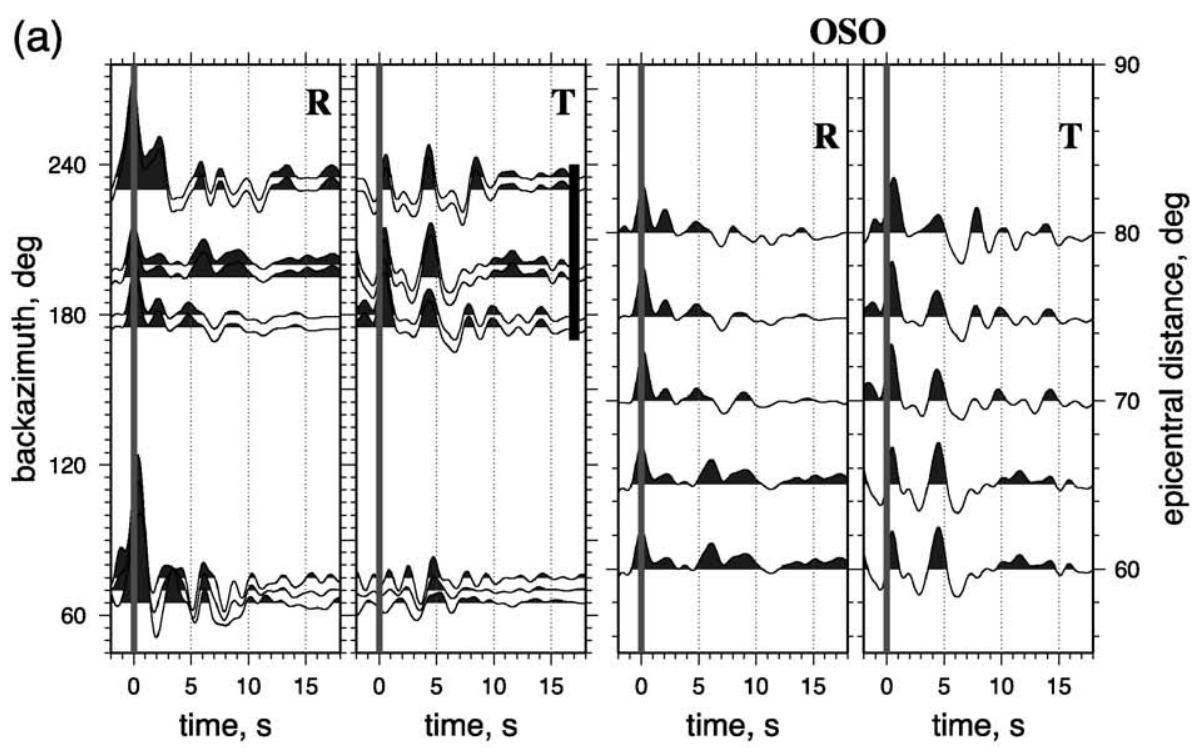

(b)
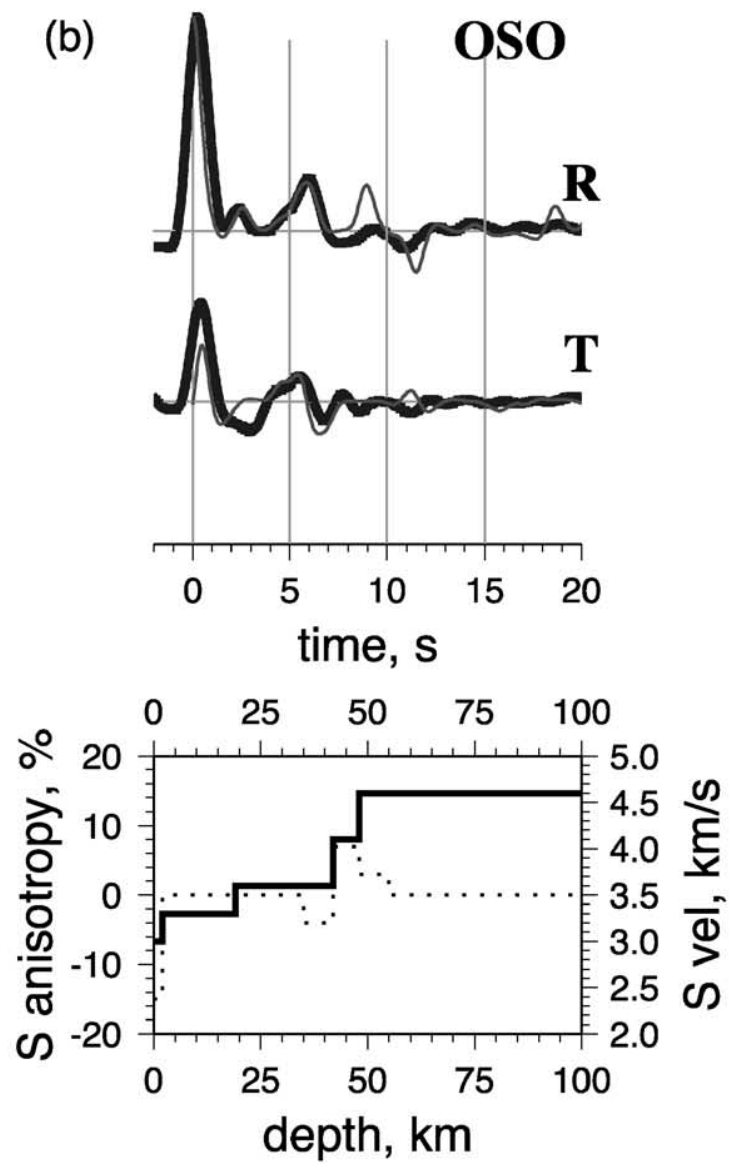

Fig. 10. (a) Same as Fig. 3a for station OSO. (b) Same as Fig. 3b for station OSO. 


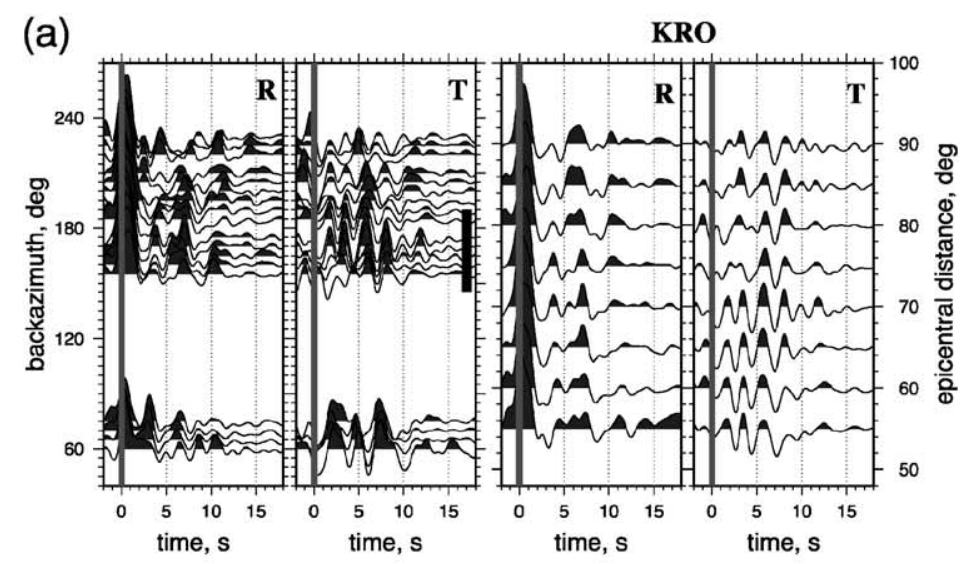

(b)

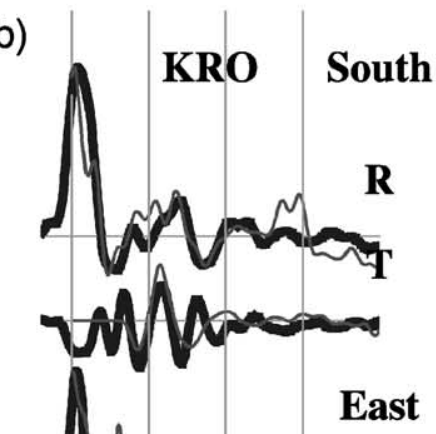




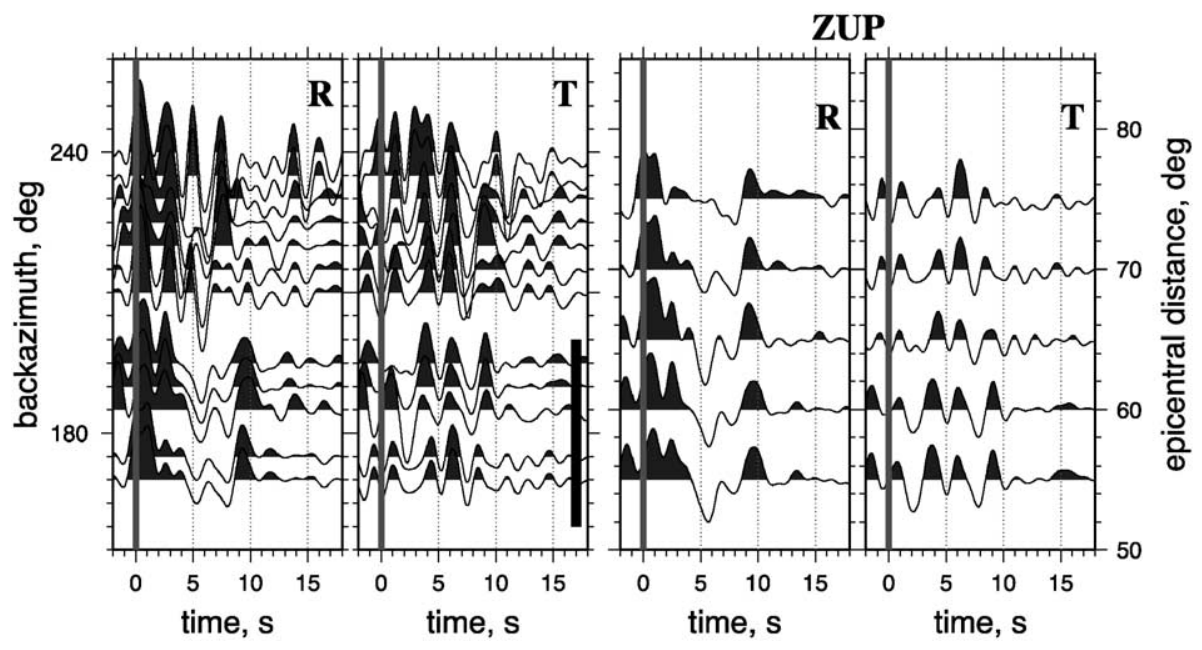

Fig. 12. Same as Fig. 3a for station ZUP.

$10-11 \mathrm{~s}$, but are much weaker and are concentrated in narrow backazimuthal ranges.

In the model for KRO (Fig. 11b, Table 1) the broad initial pulse on the radial component is reproduced by placing a layer of very low velocity at the surface, while radial energy in the 5-7.5-s time window arises through conversion at velocity interfaces at 30,33 and $48 \mathrm{~km}$. Similar to the case for OSO, the crust-mantle transition appears to be gradational between 30 and $40 \mathrm{~km}$. Multiple rever-

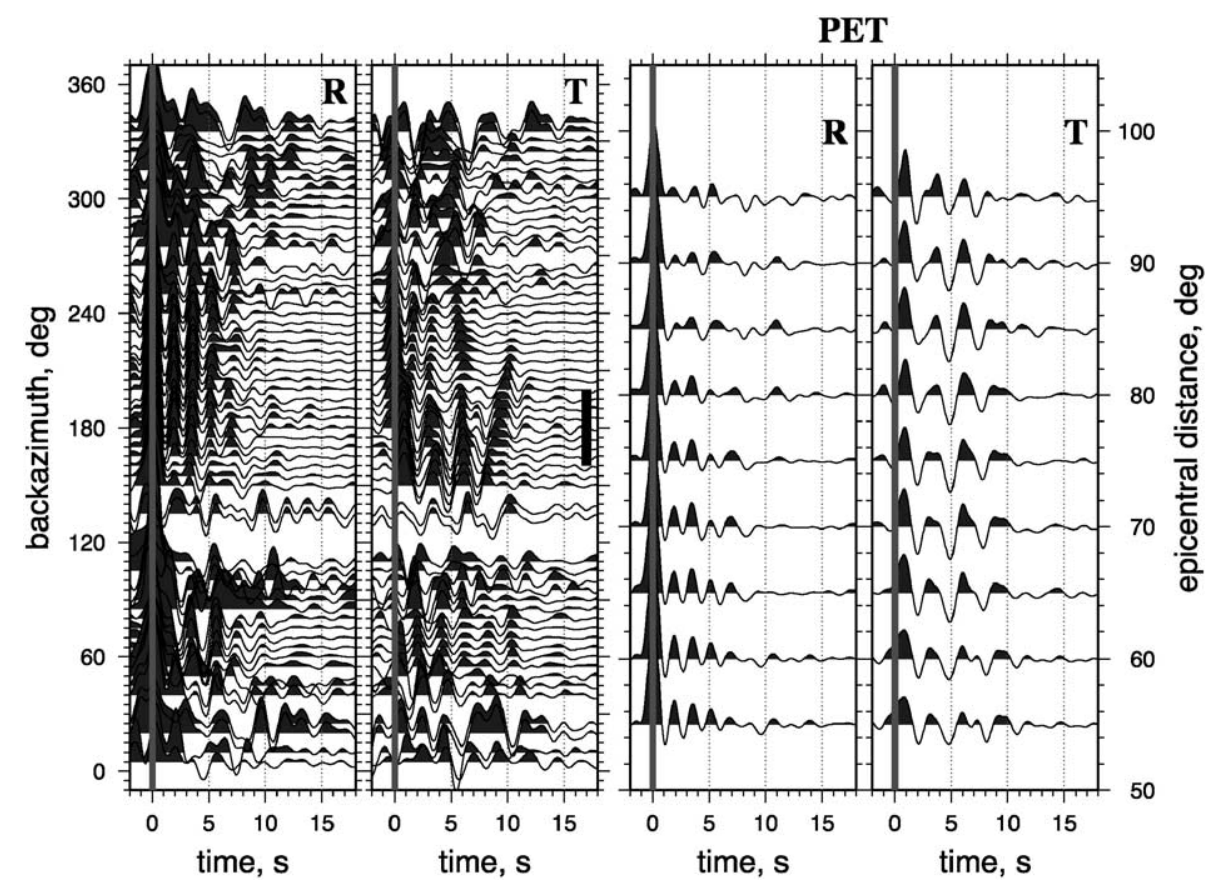

Fig. 13. Same as Fig. 3a for station PET. 
berations from upper-crustal velocity contrasts (2and $13-\mathrm{km}$ deep) merge with direct arrivals from the low-velocity mantle layer to form a broad negative radial phase centered at $8 \mathrm{~s}$ on the southern RF. A change of uppermost layer thickness from 2 to $4 \mathrm{~km}$ yields radial RFs that match observations from the east in the early part of the trace. The match deteriorates beyond $5 \mathrm{~s}$.

To reproduce the behavior of the transverse component, we introduced two anisotropic layers in the mantle, with fast anisotropic axes having a common value of $\varphi=300^{\circ}$, and inclined in opposite directions $\left(\theta=130^{\circ}\right.$ in the upper layer, $\theta=50^{\circ}$ in the lower). This combination produces a threeswing phase that faithfully reproduces backazimuthdependent behavior seen in the data.

\subsection{3. $Z U P$}

Station ZUP recorded useful data from the southern source region only (Fig. 12). Radial RFs show significant differences between backazimuthal ranges $170^{\circ}-200^{\circ}$ and $210^{\circ}-240^{\circ}$. This rapid variation, together with the large amplitude of radial pulses up to $10 \mathrm{~s}$ in the RF, suggests that the pattern is formed by reverberations close to the surface. Lateral changes in properties and/or topographic effects are likely. The transverse pattern is much more uniform throughout the range of observations, with a sequence of two positive pulses at 4.5 and $6.5 \mathrm{~s}$ separated by a negative pulse. Also, a two-sided (negative-positive) pulse arrives in the $7.5-10$-s time window, becoming later from east to west. Due to the complicated pattern of reverber-
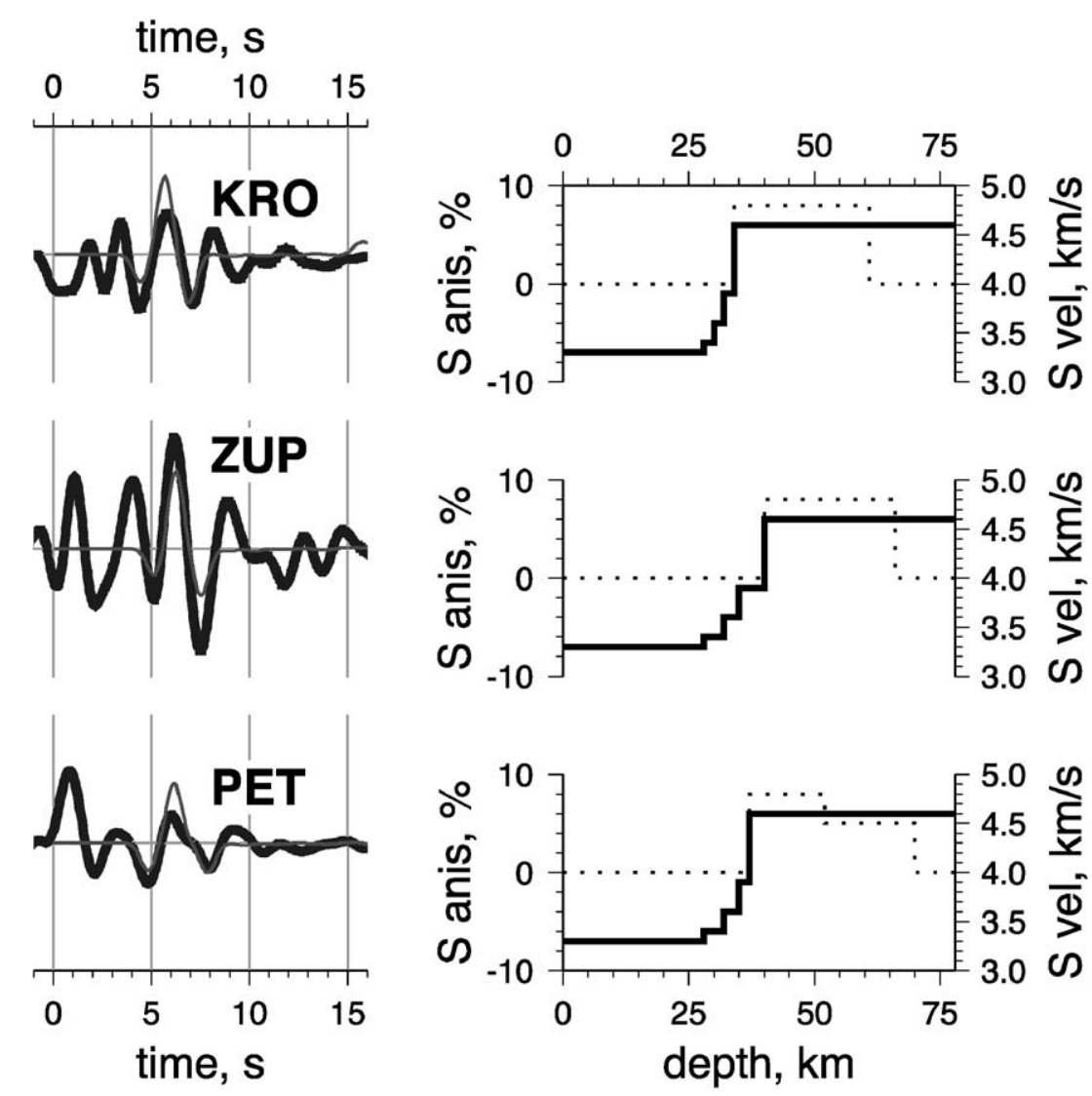

Fig. 14. Left: Comparison of averaged transverse receiver functions computed for stations KRO, ZUP and PET for southern backazimuthal sectors. A sequence of pulses between 3.5 and $8 \mathrm{~s}$ appears to be very similar in all three traces. Synthetics (shown in thin lines) are computed for models illustrated on the right. Conceptual models are built on the basis of the model for KRO. See text for details. 
ations on the radial component, we are unable to develop a model for the vertical velocity structure at ZUP. As discussed below, the regular transverse pattern in the 4-7-s time window may be reproduced with a combination of two anisotropic layers in the upper mantle. Without constraints from the $P-S V$ wavefield, the RFs constrain mantle structure only in a qualitative way.

\subsubsection{PET}

The RF pattern for station PET (Fig. 13) has been previously discussed by Park and Levin (2000), and is shown here for completeness of the presentation. The multi-year data set available for PET illustrates the resolving potential of the MTC RF-estimation technique, given a large data set. The mantle under the station is sampled by body-waves from most backazimuth angles, with only a handful of gaps. A larger amount of data results in more efficient suppression of noise and spurious phases, and better delineates stable features. However, the limitations of the technique become apparent as well. As Park and Levin (2000) found, the reverberatory pattern in the first 5-7 s of the radial RF likely arises from a process other then upgoing body-wave mode conversion. Distinct spectral peaks in the coherence between the radial and vertical components are diagnostic of the reverberations of a shallow (perhaps $1 \mathrm{~km}$ ) low-velocity layer, consistent with the extensive volcanoclastic deposits beneath the city of Petropavlovsk. As a result, we cannot recover the model of $V_{\mathrm{P}}$ and $V_{\mathrm{S}}$ variation with depth, as the pattern of upgoing $P-S V$ phases is obscured.

As will be shown below, the transverse pattern observed for southern $\left(170^{\circ}-190^{\circ}\right)$ backazimuths appears similar to those seen at ZUP and KRO, and is likely to represent subsurface structure common to the mantle-wedge corner of the Kamchatka volcanic arc. Also, a transverse conversion at 810 -s delay time becomes progressively later from backazimuth $155^{\circ}$ to $230^{\circ}$, and so likely arises from structures associated with the subducting slab.

\subsubsection{Qualitative model for mantle anisotropy at ZUP and PET}

While complications in radial RFs at stations ZUP and PET prevent us from developing models for the vertical velocity distribution, we can explore the distribution of seismic anisotropy under the east coast of Kamchatka on the basis of transverse RFs. As Figs. 14 and 18 illustrate, there appears to be a great deal of similarity in the first $10 \mathrm{~s}$ of transverse RFs observed from the south at KRO, ZUP

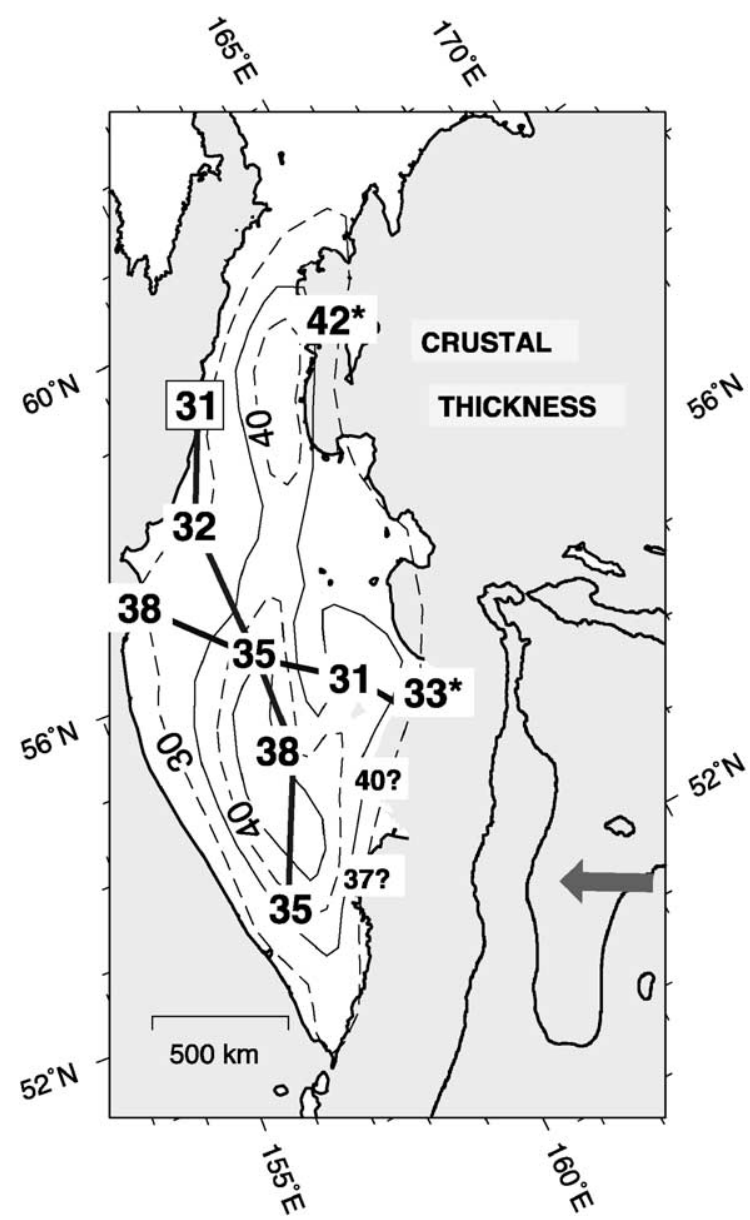

Fig. 15. Crustal thickness values derived from individual models. Depth to the bottom of the lowest layer with $V_{\mathrm{S}}<4.0 \mathrm{~km} / \mathrm{s}$ is shown. Asterisks mark sites where we believe the transition is gradational. Values for ZUP and PET are derived on the basis of comparing their transverse RFs with that of KRO, and thus are shown with a question mark. Thick solid lines show traces of the profiles presented in the following figure. Black arrow shows the direction of convergence along the Kamchatka trench. Thin black lines in the ocean denote the depth contour of $5500 \mathrm{~m}$, providing an outline of the Kamchatka and Aleutian deep-water trenches. Thin dashed and solid lines denote Moho depth distribution, with depth in kilometers annotated, adapted from Bogdanov and Khain (2000). 
and PET. At KRO, we are able to resolve the depth-dependent velocity structure, and find that the transverse RF pattern is well represented by a sequence of two anisotropic layers in the mantle, both having a fast symmetry axis with $\varphi=300^{\circ}$, but inclined in opposite directions (see Table 1). We use the anisotropy-depth distribution at KRO as a template for ZUP and PET, adjusting the depth of anisotropy to match observed waveforms. The distribution of isotropic velocity is designed to produce minimal signal on the radial component. Realistic features in models for ZUP and PET are the depths where anisotropy has to start, stop and undergo change. Taken at face value, these models suggest thicker crust at ZUP, and mantle anisotropy at larger depths under PET.

\subsection{Other portable stations}

\subsection{1. $S B L$ and $K G B$}

Stations SBL (on the west coast) and KGB (on the east coast, at the junction with the Aleutian Arc) presented RF data sets that are rendered unusable by reverberations that do not appear to arise from depth conversions. In both cases signal levels on the transverse component are equal to or surpass those on the radial, and the RFs are dominated by pulses with periods over 2 s. Back-

(a) South

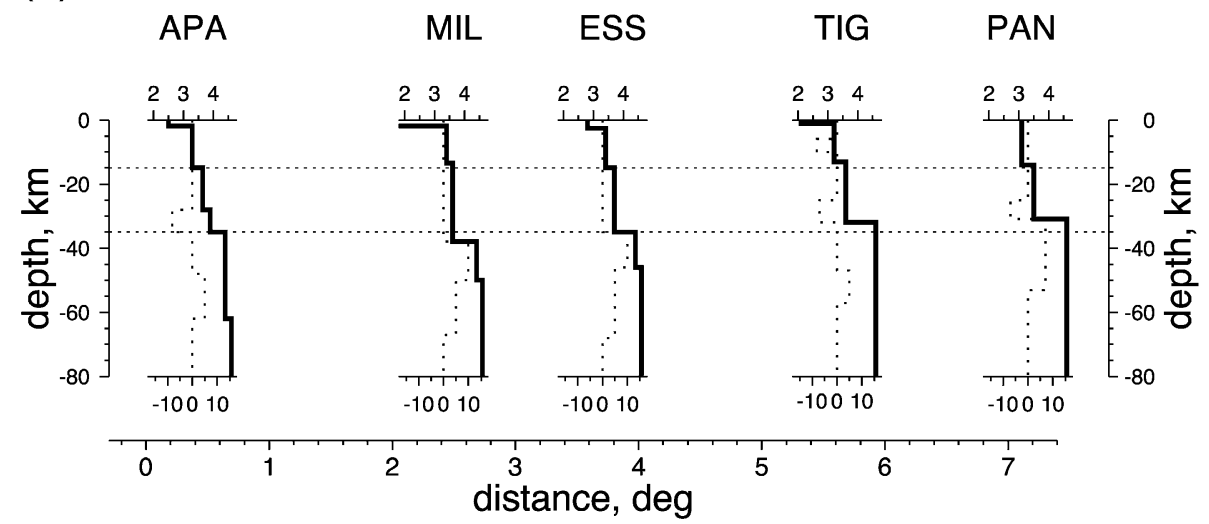

(b) East

West

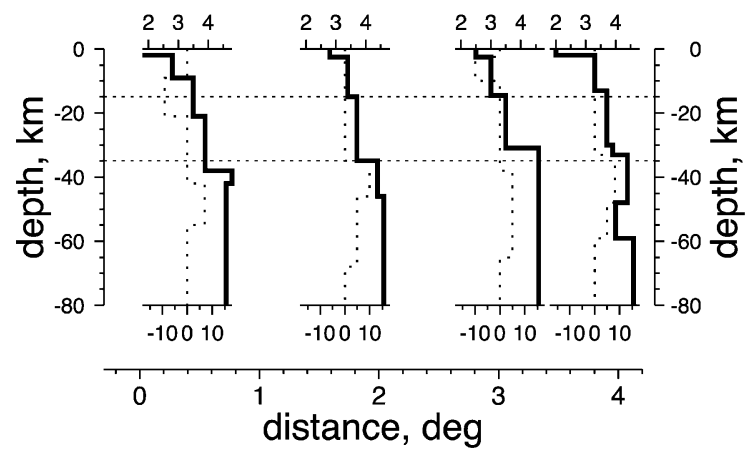

Fig. 16. Profiles of lithospheric properties through central Kamchatka. Solid lines show values of $V_{\mathrm{S}}$ (scale on top), dashed lines show values of anisotropy, in peak-to-peak percent of $V_{\mathrm{S}}$ (scale on the bottom) (a) from APA to PAN, and (b) from UHR to KRO. See Fig. 15 for profile locations. 
azimuthal and epicentral distance RF gathers are presented in Appendix A for comparison purposes.

\subsubsection{PZT, TKI, BNG}

Data observed at stations PZT (the southernmost node of the network) and TKI (the northernmost node) show evidence of strong wavefield perturbation. Body waves arriving from certain directions exhibit gross mismatch with predicted polarizations. Both stations were affected by sensor malfunctions which at the time of this writing are poorly understood, and may be the cause of the observed wavefield perturbation. We chose not to interpret these data at this time. Station BNG, on the last island of the Aleutian chain, will be a subject of a separate study.

\section{Overview of results}

Receiver functions for the stations of the portable network generally yielded clear phases that could be associated with the crust-mantle transition. Fig. 15 presents a broad view of the crustal thickness for the upper plate of the Kamchatka subduction zone, generated from models developed to match observed RFs. We use the lower boundary of the layer with $V_{\mathrm{S}} \leq 4 \mathrm{~km} /$ $\mathrm{s}$ as the measure of the crustal thickness. Our assumption of fixed $V_{\mathrm{P}} / V_{\mathrm{S}}=1.75$ will cause us to underestimate crustal thicknesses if the lower crust is gabbroic, but biases are unlikely to exceed $\sim 2 \mathrm{~km}$, according to the rock properties tabulated by Christensen (1996). In two instances (stations KRO and OSO on the east coast), we believe that the crust-mantle transition is gradational, and show the values for the "base" of our model crust with an asterisk. Moho depths for ZUP and PET are shown with a question mark. They are inferred from the transverse RFs only, as the radial RFs are overprinted with shallow resonances.

Our stations are too widely spaced for effective RF migration (e.g., Yuan et al., 1997), but linear profiles of single-station velocity models are instructive. Fig. 16 presents two profiles of lithospheric properties, one along the Kamchatka Peninsula from the village of Apacha to the town of Palana, and the other approximately across Kamchatka, from the village of Ust'Haryuzovo to the Kronotski peninsula. Excluding four sites on the east coast where the crust-mantle transition is uncertain, the estimates of crustal thickness through- out the region are between 30 and $40 \mathrm{~km}$. Features present in most models of the Kamchatkan lithosphere are an increase in seismic velocity at $15 \pm 3 \mathrm{~km}$, a 1-4$\mathrm{km}$-thick low-velocity layer at the top of the crust, and anisotropic layers near the crust-mantle transition.

Multiple anisotropic layers in the mantle, at depths of $40-70 \mathrm{~km}$, are almost universal. A typical model involves at least two layers, with strongly differing directions of symmetry axes. At a number of sites we

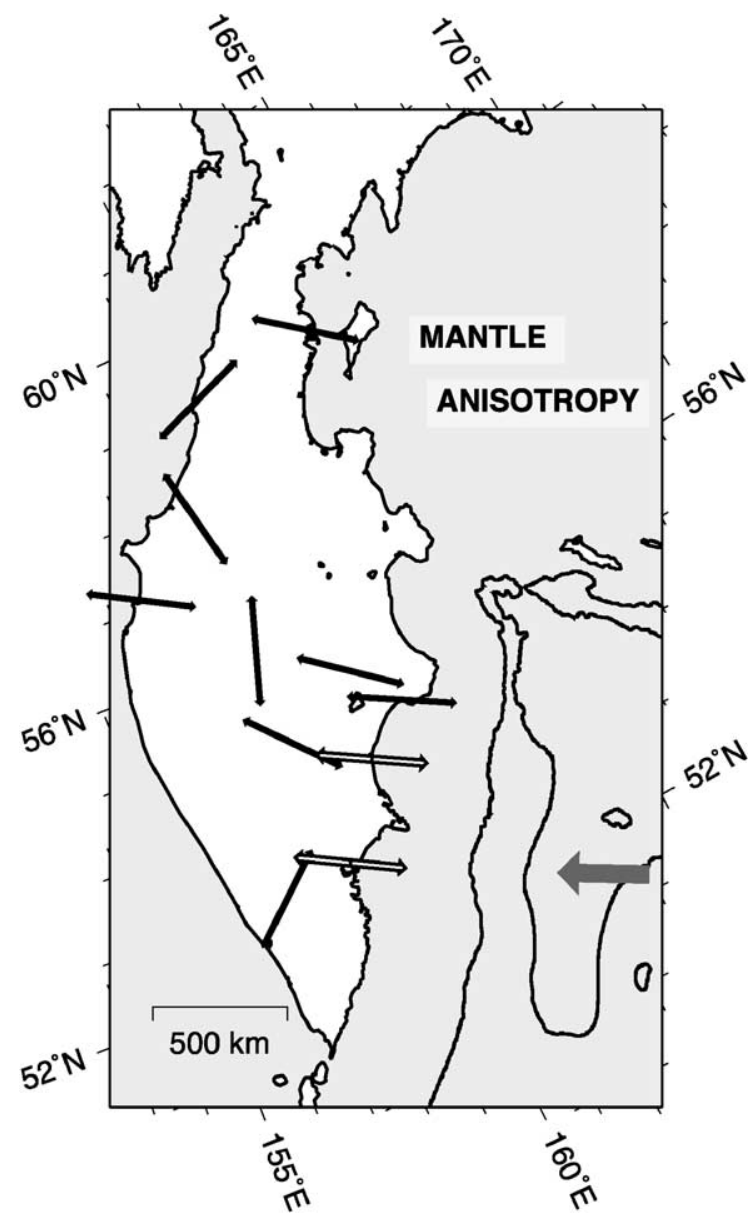

Fig. 17. Seismic anisotropy orientation in the upper mantle under Kamchatka. Orientations of anisotrpic symmetry axes derived from individual models are plotted by black arrows centered on sites. Open arrows at ZUP and PET show directions inferred through comparative analysis of transverse RFs for PET, ZUP and KRO. Black arrow shows the direction of convergence along the Kamchatka trench. Thin black lines in the ocean denote the depth contour of $5500 \mathrm{~m}$, providing an outline of the Kamchatka and Aleutian deep-water trenches. 
also find evidence for strongly anisotropic layers within the crust. In many cases the boundaries of anisotropic layers do not coincide with strong velocity contrasts. In forward-modeling the RFs, the direct
Ps conversion from a mid-crustal interface, predicted at $\sim 2$-s delay, often merges with near-surface $P S$ reverberations. Multiple reverberations from a midcrustal interface, however, appear to match Ps con-
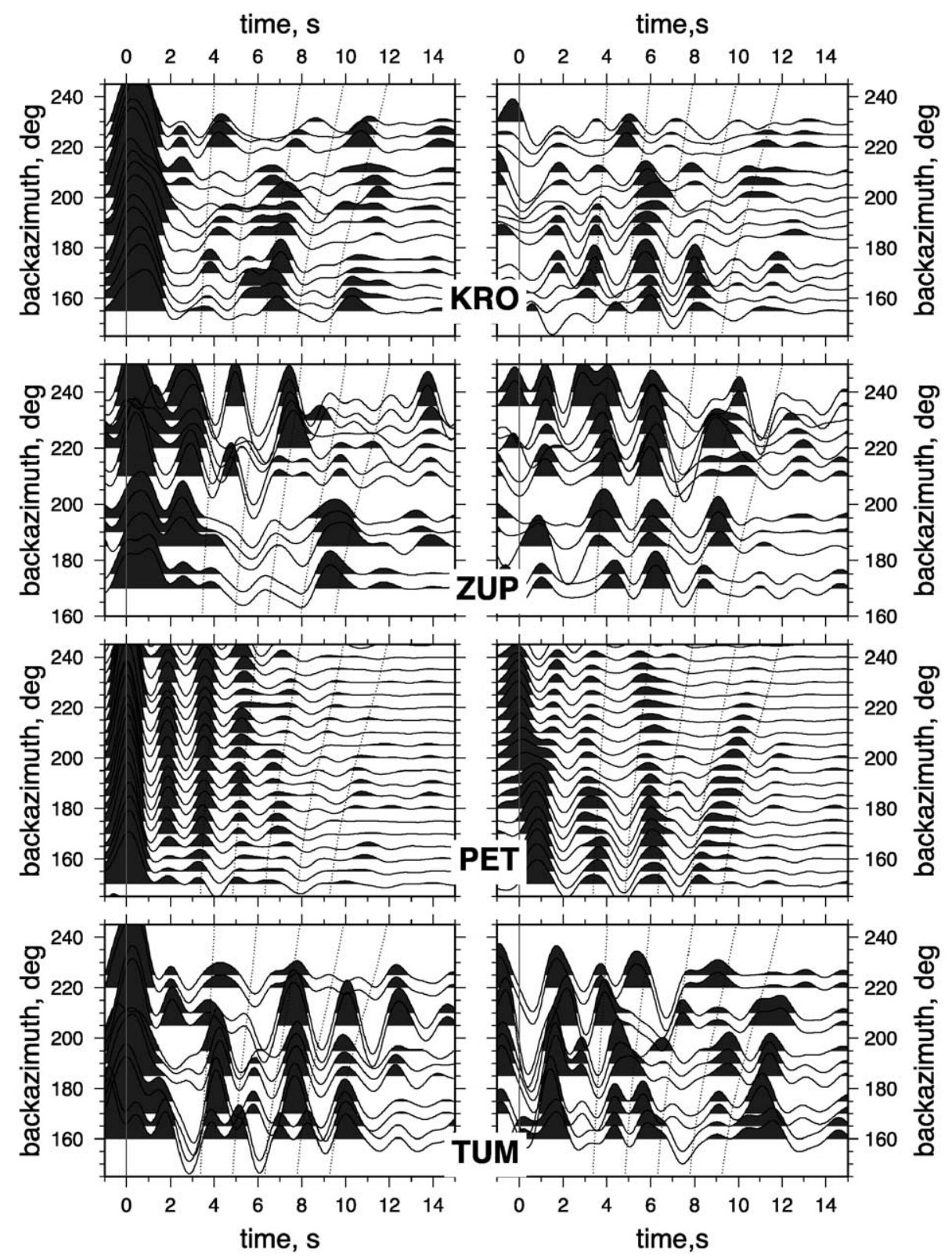

Fig. 18. Receiver functions computed for stations KRO, ZUP, PET and TUM for backazimuthal sector $150^{\circ}-250^{\circ}$. Note similarity in the pattern of transverse components at PET, ZUP and KRO. Thin lines show predicted arrival times for $P s$ converted phases generated from a dipping interface at a range of depths. The interface dips $55^{\circ}$ from the horizontal to the northwest. Interface depth directly under the station varies between 50 and $150 \mathrm{~km}$, in $25-\mathrm{km}$ intervals. 
verted-wave energy that follows the direct Moho $P S$ conversion on the radial RFs, obviating a search for large velocity interfaces just below the Moho.

The orientations of anisotropic axes in the horizontal plane which our models predict for the upper mantle are shown in map view in Fig. 17. At two sites on the east coast (PET and ZUP), we infer the anisotropic direction on the basis of similarity in transverse RF patterns (Figs. 14 and 18), not through direct modeling. These cases are shown by open arrows. A trench-normal orientation of anisotropy is inferred along the entire east coast of Kamchatka, and also at some sites in the western peninsula, while some sites in the interior of the peninsula have nearmeridional orientation of anisotropic symmetry axes.

\section{Discussion}

\subsection{RF modeling caveats}

In RF modeling, velocity values and layer thicknesses are linked via a trade-off relationship, and thus our models are not uniquely determined. We have most confidence in features such as the number and strength of significant velocity contrasts, the depth regions where anisotropy is required, and the orientation of anisotropy-inducing fabric. The precise depths of interfaces are subject to a trade-off with $V_{\mathrm{P}} / V_{\mathrm{S}}$ ratio. The presence of "slow" and "fast" symmetry is assumed for crust and mantle, respectively, aside from certain scenarios discussed below. A change of the fast/slow assumption leads to a rotation of the inferred symmetry axis, as explored by Levin and Park (1998).

Our models have more parameters then is typical in receiver function modeling. In addition to thickness and velocity, each layer has three parameters that define anisotropic properties. In developing our models, we introduce only as many layers as is required to capture the behavior of the chosen features in the data, while ignoring parts of the observed waveform deemed unrelated to the velocity structure at depth. Unlike the search for a vertical velocity profile that would fit a pattern of $P-S V$ converted phases (e.g., Ammon et al., 1990; Sandvol et al., 1998), our approach does not lend itself easily to automation via an inversion scheme. We suspect that the assumption made in an automated RF inversion, i.e., that all waveforms in an RF trace represent energy scattered in a $1 \mathrm{D}$ structure, may be misleading. This assumption is violated in much of the data we obtained in Kamchatka because many RF features do not appear at all or most backazimuths.

Levin and Park (1997a,b) and Savage (1998) documented the ambiguity of interpreting transverse RFs with horizontal anisotropic structures or inclined isotropic structures. The real structures are likely to be both anisotropic and inclined. Our experience shows that in most cases one of the two mechanisms dominates, and thus may be explored separately. Examples include phases from the slab at PET, where the $P s$ moveout matches the predicted slab dip, and signals from the crust-mantle transition at most sites, likely due to effective anisotropy of the medium. We favor treating $\mathrm{SH}$-polarized pulses that lag first-arriving $P$ by $3-6 \mathrm{~s}$ as arising through anisotropic $P-S H$ conversion, due to their strength, their multi-cyclicity and small temporal moveouts with direction. As shown by Levin and Park (1997a,b), anisotropy is more efficient in generating these effects near the Moho than inclined velocity interfaces. In the uppermost crust, modeling suggests that energy on the transverse component at zero- or near-zero-delay relative to direct $P$ can arise through deflection of the $P$-wave particle motion by an inclined interface, as efficiently as by $P-S H$ conversion. When $P$ deflection takes place close to the surface, its effect is much harder to distinguish from that of anisotropy in the near-surface layer, as discussed above for the station MIL.

\subsection{Crustal thickness and sub-Moho mantle velocities}

It is useful to compare our estimates of crustal thickness with previously published results. Discrepancy between our crustal thickness estimates and the map of Bogdanov and Khain (2000) is seen in the central depression of Kamchatka, where our estimates are smaller by 5 to $8 \mathrm{~km}$. An exception is our site UHR, where our crustal thickness estimate exceeds those of Bogdanov and Khain (2000) by $8 \mathrm{~km}$. These discrepancies are instructive, as they reflect assumptions and interpretations from a variety of geophysical tools. In our work, mode-converted body waves from teleseismic earthquakes sample a small volume below the observation point. In the interpretation of observed 
wavefield we operate with distinct velocity contrasts, while in reality these may be gradational changes. Overview maps of crustal thickness, like that of Bogdanov and Khain (2000), are compiled using gravity data, calibrated by active-source seismic work on land and offshore. Such compilations likely involve a large degree of lateral smoothing, and the interpretation of Moho depth from gravity data depends critically on a priori knowledge of crustal density. Crustal density is not well known in Kamchatka, and is likely to be laterally variable. Also, difficulties in resolving the Moho in refraction profiles were noted by Balesta and Gontovaya (1985). We conclude that the discrepancies between our crustal thickness estimates and those of Bogdanov and Khain (2000) may stem largely from differences in modeling assumptions and data constraints. An independent set of data constraints, e.g., regional surface wave dispersion, may be required to resolve the issue.

For a large fraction of our sites on the Kamchatka peninsula, the RF models predict unusually low values for $V_{\mathrm{P}}$ in the subcrustal mantle (Table 1). $V_{\mathrm{P}}$ may be biased downward somewhat by the fixed $V_{\mathrm{P}} / V_{\mathrm{S}}$ ratio. While $\mathrm{RF}$ inversion provides constraints on relative changes in velocity values only, we consider low $V_{\mathrm{P}}$ plausible in view of corroborating evidence from other work, and perhaps the presence of elevated geotherms in the arc setting. In their original study, Fedotov and Slavina (1968) reported low $V_{\mathrm{P}}(\sim 7.5 \mathrm{~km} / \mathrm{s})$ at depths $30-50 \mathrm{~km}$ under the central Kamchatka depression. Using regional surface waves, Shapiro et al. (2000) reported $V_{\mathrm{S}} \sim 4.2$ $\mathrm{km} / \mathrm{s}$ in the subcrustal part of their model for the peninsula.

\subsection{Phases from the slab}

RFs computed for stations in southeastern Kamchatka should contain converted phases from the interface between the subducting Pacific plate and the overlying mantle. Given the steep angle of descent for the slab under Kamchatka, we expect such phases to exhibit characteristic moveout with backazimuth. Using a model for the slab surface from Gorbatov et al. (1997), we examine our backazimuthal RF gathers for the presence of phases that would fall on the moveout lines predicted from the dip and depth of the slab interface. Fig. 18 shows RF gathers for all stations where we believe slab-related phases are present. Lines on the figure show predicted times for the $P s$ converted phase from a single dipping interface at a variety of depths. The interface dips $55^{\circ}$ from horizontal to the northwest (downdip azimuth $300^{\circ}$ ). Depth of the interface under the station (i.e., along a vertical line) is varied between 50 and $150 \mathrm{~km}$, in $25-\mathrm{km}$ intervals. Computations (after Langston, 1977b) are done using isotropic-media ray theory, assuming a plane wave that impinges a medium composed of a layer above a mantle wedge, separated from a halfspace by an inclined interface. $V_{\mathrm{S}}$ in the halfspace is $4.6 \mathrm{~km} / \mathrm{s}$, while $V_{\mathrm{S}}$ above the interface is computed as an average between a 35 $\mathrm{km}$-thick layer with $V_{\mathrm{S}}=3.6 \mathrm{~km} / \mathrm{s}$, and the remainder of the depth column to the interface having $V_{\mathrm{S}}=4.6$ $\mathrm{km} / \mathrm{s}$. As in the rest of this paper, $V_{\mathrm{P}} / V_{\mathrm{S}}=1.75$ is assumed.

The clearest evidence for the slab-related phase comes from the long-running station PET. A twosided transverse phase between 7 and 10 s clearly follows predicted moveout curves for interfaces at 125 and $150 \mathrm{~km}$ beneath the station. Slab depth under PET is predicted to be slightly in excess of $100 \mathrm{~km}$ (Fig. 1). The two-sided shape of the pulse implies that it originated from a layer or a group of layers, not a single interface.

Portable observatories ZUP, KRO and TUM did not acquire enough data for similar image clarity, but available results are encouraging. At KRO, where depth to the slab is $\sim 70 \mathrm{~km}$, the slab-converted phase should be at $5.5-6 \mathrm{~s}$. The transverse phase seen in this time window can be modeled with horizontal structures (see the previous section), and is also seen at ZUP and PET where the slab is deeper. While slabconverted energy is likely to be present, it is probably not the sole source of the observed KRO RF. We note that radial RFs at KRO show a two-sided pulse between 7 and $9 \mathrm{~s}$ that exhibits moveout expected from a slab-converted phase. The inferred interface depth exceeds $100 \mathrm{~km}$, pointing possibly to an interface within the subducting slab. It is also interesting to note that the $1 \mathrm{D}$ velocity structure developed to match radial RFs at KRO contains a low-velocity zone between 48 and $59 \mathrm{~km}$ (Fig. 11b, Table 1).

At station ZUP the slab is $\sim 100-\mathrm{km}$ deep, and may be responsible for phases arriving on transverse RFs between 7 and $10 \mathrm{~s}$. Earlier transverse phases, 
seen between 3.5 and $6 \mathrm{~s}$, do not follow predicted moveout curves, and thus are likely to be associated with horizontal features above the dipping slab. At station TUM, where depth to the slab is $\sim 150 \mathrm{~km}$, transverse phases between 9 and $13 \mathrm{~s}$ exhibit characteristic moveout, and thus are consistent with a slab interface. Phases that appear on the radial component, on the other hand, do not follow the moveout curves, and must be associated with structures unrelated to the subducting Pacific plate.

\subsection{Anisotropy and strain in the mantle wedge}

The inferred strength of shallow anisotropy in the supra-slab mantle wedge argues that the crust-mantle transition represents an important shear zone in the Kamchatka tectonic system. At face value, this suggests that mantle "lithosphere," in the sense of a semi-rigid peridotite foundation for the $30-40-\mathrm{km}$ continental crust, may not exist in Kamchatka. It is possible for the strain that we infer to be fossil, rather than active, deformation. However, any fossil strain would also be the result of subduction processes in a mantle-wedge setting, associated with the Mesozoic Olyutorsky arc terrane that comprises the eastern third of Kamchatka.

The trench-normal strike of many inferred anisotropic fast axes is consistent with mantle-wedge flow that is driven by shear coupling to the descending slab. (The inclination angle of the inferred anisotropic fast axes is less easy to explain, see below.) There is a preponderance of trench-normal orientations along the east coast, with the caveat that PET and ZUP are interpreted as trench-normal on the basis of close similarity in the transverse RF with KRO and TUM. Trench-normal fast-polarization axes at UKH, TIG and OSO are less plausibly related to present-day subduction. However, subduction under OSO in northern Kamchatka was active until no more than $10 \mathrm{Ma}$ (Hochstaedler et al., 1994; Honthaas et al., 1995). Stations UKH and TIG lie astride the western mountain range of Kamchatka, which is a relict of a late Mesozoic and early Cenozoic subduction zone that became extinct with the collision of the Olyutorsky terrane (Geist et al. 1994). If trench-normal subMoho mantle fabric under TIG, OSO and UKH is related to subduction processes, this fabric likely reflects fossil, not dynamic, strain.
The inferred anisotropic fast axes of stations APA, MIL and ESS, all either within or adjacent to the central depression of Kamchatka, are somewhat variable, and may reflect 3D complexities in the deformation of the mantle wedge. In particular, Peyton et al. (2001) argue that trench rollback causes a transfer of asthenospheric mantle from the Pacific to the Kamchatkan side in the vicinity of the Aleutian corner, as evidenced by trench-normal shear-wave splitting observed at stations KGB and ESS. Peyton et al. (2001) interpret weak splitting and a trench-normal fast polarization axis at ESS to arise from mantle flow at depths $>100 \mathrm{~km}$, beneath the tattered edge of the Kamchatka slab. Such flow would not rule out the development of trench-parallel extension and/or flow in the mantle immediately beneath the Moho under ESS, as indicated by RF analysis. Trench-normal fabric has typically been inferred in the back-arc regions affected by trench rollback (e.g., Margheriti et al., 1996), so a significant 3D slab-edge effect on flow geometry would need to be invoked to explain the ESS observations. We note, however, that a shallow trench-parallel anisotropic fabric has been inferred for the Northern Apennines mantle wedge by Mele et al. (1998) and Hearn (1999), so our Kamchatka observations have a precedent.

In the mantle wedge, two layers of anisotropy appear required to match the transverse RF, especially for east-coast stations KRO, TUM, ZUP and PET. This suggests that the mantle "lithosphere" beneath Kamchatka is actively deforming. Although the inferred fast axes in the mantle wedge are trench-normal, their inclination relative to the horizontal is unexpected (Fig. 19). If the associated olivine LPO follows the extension associated with simple shear, the upper anisotropic layer can be related to trenchward traction exerted by the overlying crust, leading to right-lateral shear as viewed in Fig. 19. The hypothetical olivine LPO is not consistent with trenchward traction from mantle flow at depth, as this shear would be left-lateral, as viewed in Fig. 19. Similarly, the tilt of the symmetry axis in the lower anisotropic layer does not fit well with right-lateral simple shear associated with the traction of the downgoing slab.

In modeling the RFs, we have assumed that olivine LPO develops with a fast axis of symmetry, but recent high-pressure deformation experiments 


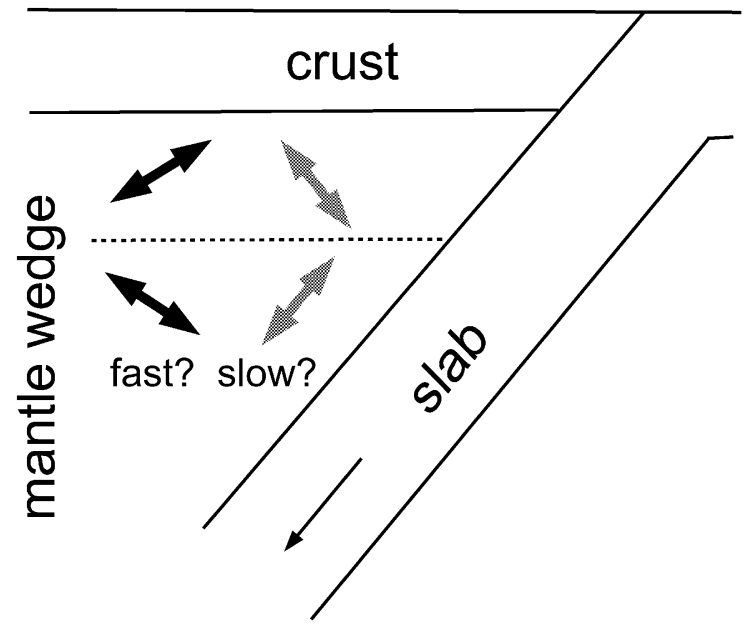

Fig. 19. Conceptual models for mantle wedge anisotropy beneath stations on the east coast of southern Kamchatka. Two layers with distinct anisotropic properties are inferred to lie within the supraslab mantle wedge. Both layers possess tilted symmetry axes with a trench-normal surface projection. If anisotropy in the mantle wedge is generated largely by olivine LPO with a fast symmetry axis that follows the direction of maximum extension (filled arrows), shallow right-lateral shear (as seen in the plane of the figure) is opposed by left-lateral shear at depth. If anisotropy in the mantle wedge is generated largely by melt lenses or tilted diapiric structure with a slow axis of symmetry (shaded arrows), the slow axis would also follow the direction of maximum extension. This scenario would imply shallow left-lateral shear (as seen in the plane of the figure) underlain by deeper right-lateral shear.

(Jung and Karato, 2001) suggest that "wet" peridotite suffers more dynamic recrystallization than "dry" peridotite, and develops a different anisotropic fabric. In particular, for "wet" peridotite the $c$-axes (intermediate) of olivine crystals align with flow instead of the $a$-axes (fast), so that bulk anisotropy with a fast axis of symmetry may not develop in volatile-rich regions within the supra-slab mantle wedge. Assuming that wet-peridotite deformation leads to negligible alignment of the olivine fast axis, anisotropy with a slow-axis of symmetry could develop from lenses of partial melt in the mantle wedge or else from fine-layering caused by smallscale diapirism. Our sparse data sets could allow a slow axis of symmetry in the mantle wedge layers, trench-normal but perpendicular to the tilted fast axis orientation (Fig. 19). For these mechanisms, a slow symmetry axis would likely align with the extension direction of a simple-shear deformation because cracks and dikes tend to align perpendicular to the principal extension axis. For a slow symmetry axis in the mantle (grey arrows in Fig. 19), the inferred extension direction in the top mantle layer is consistent with left-lateral simple shear exerted by trenchward mantle flow at depth.

A composite scenario is possible with left-lateral shear in both layers of the mantle wedge, if slow axis anisotropy pervades the upper layer and LPO fast axis anisotropy pervades the lower layer. This scenario would imply that water, melt lenses and/or sheeted diapirs are abundant in the top $\sim 15 \mathrm{~km}$ of the mantle, but not deeper. In this composite solution anisotropy could be generated without a flow reversal in the mantle wedge, e.g., by shear-coupling to the downgoing slab, or else by the suction of the downgoing slab as it swings (hypothetically) toward a steeper dip. Yuan et al. (submitted for publication) demonstrates for GSN station COR (Corvallis, OR, USA) that it is possible to discriminate between tilted fast and slow symmetry axes in anisotropic layers, given sufficient backazimuthal coverage. Unfortunately, the portable network in Kamchatka has a small number of clean teleseismic $P$ waves relative to the Yuan et al. (submitted for publication) data set, and interpretation of the more numerous teleseisms at GSN station PET is hampered by local resonances. Final resolution of this issue may await RF analysis of $P$ waves from Kamchatka slab events, where higher frequencies and a wide variation in incidence angles complicate the construction of composite RF sweeps. We hope to address this data at a later date.

\section{Acknowledgements}

This research was supported by the NSF grants EAR-9614639 (data collection and archiving) and EAR-9805206 (data analysis). The resourcefulness of the Kamchatka Experimental-Methodical Seismic Department (V. Chebrov, O. Dontsov, E. Tokarev, V. Stepanov, V. Sinitsyn, N. Titkov, I. Semchenko) and support from the Institute of Volcanology (V. Gorelchik, A. Osipenko, L. Osipenko) were critical to the success of the field campaign. Creative cargo handling by Reeve Aleutian Airlines is appreciated. Support from the IRIS PASSCAL staff (Matthew 


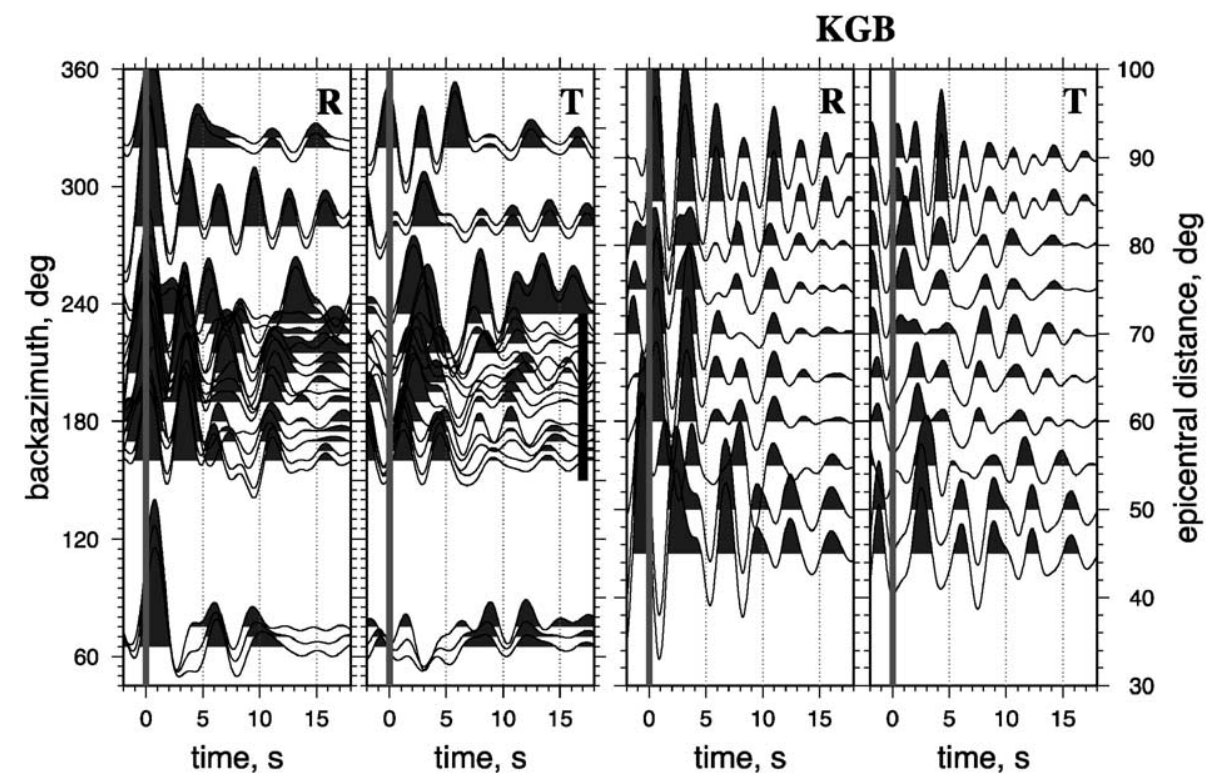

Fig. A1. Receiver functions for station KGB. Thick solid line denotes backazimuthal range used in constructing the epicentral sweep.

Fouch, Paul Friberg, Noel Barstow, Doug Johnson, Mary Templeton) and from Rick Benson at the IRIS DMC is acknowledged with gratitude. Conversations with Mikhail Kogan about Russian gravity surveys were helpful. We used GMT software (Wessel and Smith, 1991) to prepare figures.

\section{Appendix A. Receiver Functions for stations SBL and KGB}

Receiver function gathers for stations SBL and KGB are presented in Figs. A1 and A2, for the sake of completeness, and also to illustrate the point that

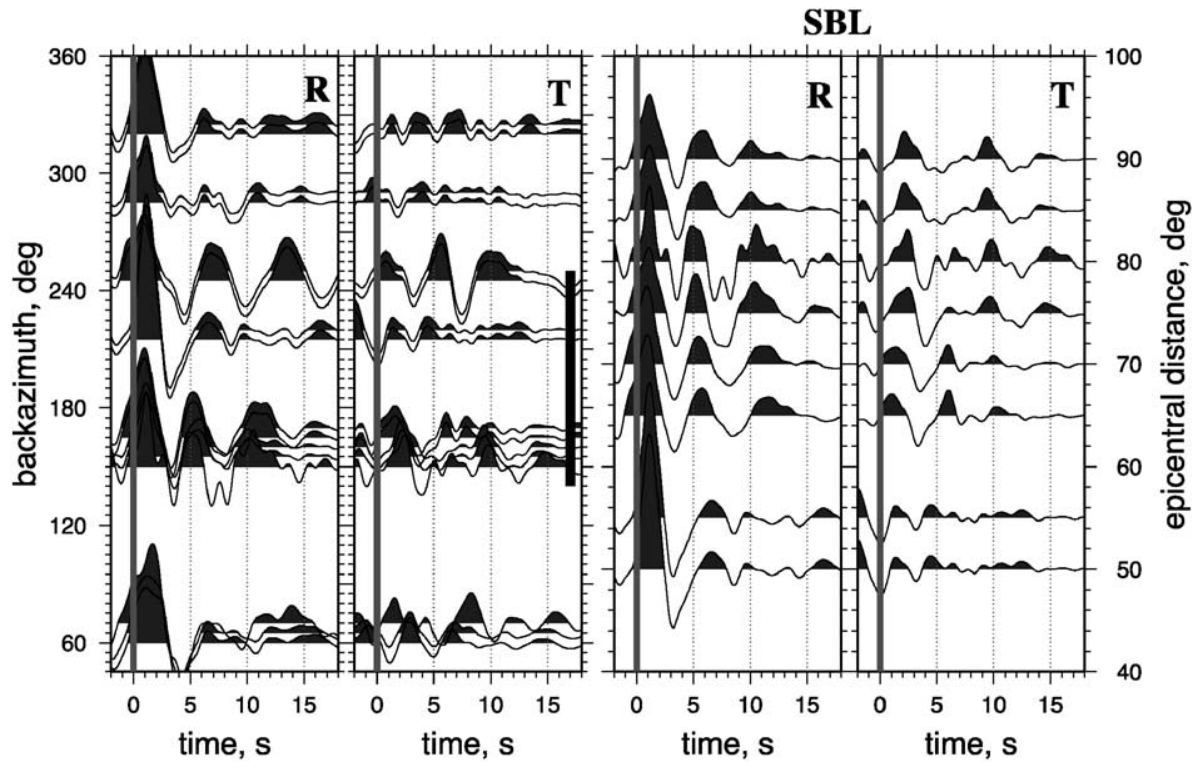

Fig. A2. Receiver functions for station SBL. Thick solid line denotes backazimuthal range used in constructing the epicentral sweep. 
data coverage alone cannot guarantee good results. At both sites, long-period resonances dominate the RF wavefield to such a degree that interpretation in terms of upgoing mode-converted body waves is not trustworthy.

\section{References}

Alvarez, W., 1982. Geological evidence for the geographical pattern of mantle return flow and the driving mechanism of plate tectonics. J. Geophys. Res. 87, 6697-6710.

Ammon, C.J., 1991. The isolation of receiver effects from teleseismic $P$ waveforms. Bull. Seismol. Soc. Am. 81, 2504-2510.

Ammon, C.J., Randall, G.E., Zandt, G., 1990. On the nonuniqueness of receiver function inversions. J. Geophys. Res. 95, $15303-15318$

Balesta, S.T., Gontovaya, L.I., 1985. Crustal structures in the Kamchatkan segment of the Pacific transition zone. J. Geod. 3, 245-257.

Balesta, S.T., Farberov, A.I., Smirnov, V.S., Tarakanovsky, A.A., Zubin, M.I., 1977. Deep crustal structure of the Kamchatkan volcanic regions. Bull. Volcanol. 40, 260-266.

Bird, P., 1979. Continental delamination and the Colorado Plateau. J. Geophys. Res. 84, 7561-7571.

Bogdanov, N.A., Khain, V.E. (Eds.), 2000. Tectonic Map of the Sea of Okhotsk Region (scale 1:250,000), with Explanatory Notes (171 pages). Institute of the Lithosphere of Marginal Seas, Russian Academy of Sciences, Moscow, Russia.

Boldyrev, S.A., 1974. Distribution of elastic wave velocities at the juncture of the Kurile-Kamchatka and Aleutian Island arcs. Trans. AN SSSR, Earth. Sci. 215, 1-6.

Bostock, M.G., 1998. Mantle stratigraphy and the evolution of the Slave province. J. Geophys. Res. 103, 21183-21200.

Buttles, J., Olson, P., 1998. A laboratory model of subduction zone anisotropy. Earth Planet. Sci. Lett. 164, 245-262.

Christensen, N.I., 1984. The magnitude, symmetry and origin of upper mantle anisotropy based on fabric analyses of ultramafic tectonites. Geophys. J. R. Astron. Soc. 76, 89-111.

Christensen, N.I., 1996. Poisson's ratio and crustal seismology. J. Geophys. Res. 101, 3139-3156.

Conrad, C.P., Molnar, P., 1997. The growth of Rayleigh-Taylor-type instabilities in the lithosphere for various rheological and density structures. Geophys. J. Int. 129, 95-112.

Cormier, V.F., 1975. Tectonics near the junction of the Aleutian and Kuril-Kamchatka arcs and a mechanism for middle Tertiary magmatism in the Kamchatka basin. Geol. Soc. Am. Bull. 86, 443-453.

DeMets, C., 1992. A test of present-day plate geometries for northeast Asia and Japan. J. Geophys. Res. 97, 17627-17635.

Dewey, J.F., 1980. Episodicity, sequence, and style at convergent plate boundaries. In: Strangway, D.W. (Ed.), The Continental Crust and its Mineral Deposits. Spec. Pap.-Geol. Assoc. Can., vol. 20 , pp. $553-573$.

Fedotov, S.A., Slavina, L.B., 1968. Estimation of longitudinal wave velocities in the upper mantle beneath north-western part of the Pacific and Kamchatka. Izv. Akad. Nauk SSSR., Fiz. Zemli 2, 8-31 (in Russian).

Fedotov, S.A., Kuzin, I.P., Bobkov, M.F., 1964. Detal'nyiye seismologicheskiye issledovaniya na Kamchatke v 1961-1963 gg (Detailed seismological studies in Kamchatka in 1961-63). Izv. Akad. Nauk SSSR, Ser. Geofiz. 9 (in Russian).

Fischer, K.M., Fouch, M., Wiens, D., Boettcher, M., 1998. Anisotropy and flow in Pacific subduction zone back-arcs. Pure Appl. Geophys. 151, 463-475.

Fujita, K., Cook, D.B., Gasgawa, H., Forsyth, D., Wetmiller, R., 1990. Seismicity and focal mechanisms of the Arctic region and the North American plate boundary in Asia. In: Grantz, A., Johnson, L., Sweeney, J.F. (Eds.), The Arctic Ocean Region (The Geology of North America). Geological Society of America, Boulder, pp. 79-100.

Geist, E.L., Scholl, D.W., 1994. Large-scale deformation related to the collision of the Aleutian arc with Kamchatka. Tectonics 13, $538-560$.

Geist, E.L., Vallier, T.L., Scholl, D.W., 1994. Origin, transport, and emplacement of an exotic island-arc terrane exposed in eastern Kamchatka, Russia. GSA Bull. 106, 1182-1194.

Giardini, D., Woodhouse, J.H., 1986. Horizontal shear flow in the mantle beneath Tonga arc. Nature 319, 551-555.

Gorbatov, A., Kostoglodov, V., Suarez, G., Gordeev, E., 1997. Seismicity and structure of the Kamchatka subduction zone. J. Geophys. Res. 102, 17883-17898.

Gorbatov, A., Dominguez, J., Suarez, G., Kostoglodov, V., Zhao, D., Gordeev, E., 1999. Tomographic imaging of the $P$-wave velocity structure beneath the Kamchatka peninsula. Geophys. J. Int. 137, $269-279$.

Gorbatov, A., Widiyantoro, A., Fukao, Y., Gordeev, E., 2000. Signature of remnant slabs in the North Pacific from $P$-wave tomography. Geophys. J. Int. 142, 27-36.

Hearn, T.M., 1999. Uppermost mantle velocities and anisotropy beneath Europe. J. Geophys. Res. 104, 15123-15139.

Hirth, G., Kohlstedt, D.L., 1996. Water in the oceanic upper mantle: implications for rheology, melt extraction and the evolution of the lithosphere. Earth Planet. Sci. Lett. 144, 93-108.

Hochstaedler, A.G., Kepezhinskas, P.K., Defant, M.J., Drummond, M.S., Bellon, H., 1994. On the tectonic significance of arc volcanism in northern Kamchatka. J. Geol. 102, 639-654.

Honthaas, C., Bellon, H., Kepezhinskas, P.K., Maury, R.C., 1995. New ${ }^{40} \mathrm{~K}-{ }^{40} \mathrm{Ar}$ dates for the Cretaceous-Quaternary magmatism of Northern Kamchatka (Russia). C. R. Acad. Sci. Paris, Ser. 2 320, 197-204.

Ida, Y., 1983. Convection in the mantle wedge above the slab and tectonic processes in subduction zones. J. Geophys. Res. 88, $7449-7456$.

Jung, H., Karato, S.I., 2001. Water-induced fabric transitions in olivine. Science 293, 1460-1462.

Karato, S.-I., Wu, P., 1993. Rheology of the upper mantle: a synthesis. Science 260, 771-778.

Kogan, M.G., Steblov, G.M., King, R.W., Herring, T.A., Frolov, D.I., Egorov, S.G., Levin, V.Ye., Lerner-Lam, A., Jones, A., 2000. Geodetic constraints on the rigidity and relative motion of Eurasia and North America. Geophys. Res. Lett. 27, 2041-2044. 
Kuzin, I.P., 1973. $P$ and $S$ wave velocities in the upper mantle of Kamchatka. Izv.-Acad. Sci. USSR, Phys. Solid Earth 2, 69-75.

Langston, C.A., 1977a. Corvallis, Oregon, crustal and upper mantle receiver structure from teleseismic $P$ and $S$ waves. Bull. Seismol. Soc. Am. 67, 713-724.

Langston, C.A., 1977b. The effect of planar dipping structure on source and receiver responses for constant ray parameter. Bull. Seismol. Soc. Am. 67, 1029-1050.

Levin, V., Park, J., 1997a. Crustal anisotropy in the Ural Mountains foredeep from teleseismic receiver functions. Geophys. Res. Lett. 24, 1283-1286.

Levin, V., Park, J., 1997b. $P-S H$ conversions in a flat-layered medium with anisotropy of arbitrary orientation. Geophys. J. Int. 131, 253-266.

Levin, V., Park, J., 1998. A $P-S H$ conversion in a layered media with hexagonally symmetric anisotropy: a cookbook. Pure Appl. Geophys. 151, 669-697.

Levin, V., Park, J., 2000. Shear zones in the Proterozoic lithosphere of the Arabian Shield and the nature of the Hales discontinuity. Tectonophysics 323, 131-148.

Margheriti, L., Nostro, C., Cocco, M., Amato, A., 1996. Seismic anisotropy beneath the Northern Apennines (Italy) and its tectonic implications. Geophys. Res. Lett. 23, 2721-2724.

Marson-Pidgeon, K., Savage, M.K., Gledhill, K., Stuart, G., 1999. Seismic anisotropy beneath the lower half of the North Island, New Zealand. J. Geophys. Res. 104, 20277-20286.

Mele, G., Rovelli, A., Seber, D., Hearn, T.M., Barazangi, M., 1998. Compressional velocity structure and anisotropy in the uppermost mantle beneath Italy and surrounding regions. J. Geophys. Res. 103, 12529-12543.

Mooney, W.D., Gettings, M.E., Blank, H.R., Healy, J., 1985. Saudi Arabian deep refraction profile, a traveltime interpretation for crustal and upper mantle structure. Tectonophysics $111,173-246$.

Mueller, S., 1977. A new model for the continental crust. In: Heacock, J.G., Keller, G.V., Oliver, J.E., Simmons, G. (Eds.), The Earth's Crust: Its Nature and Physical Properties. Geophys. Monogr., vol. 20. American Geophysical Union, Washington, DC, pp. 289-317.

Otsuki, K., 1989. Empirical relationships among the convergence rate of plates, rollback rate of trench axis and island-arc tectonics: "laws of the convergence of plates". Tectonophysics 159 , $73-94$.

Park, J., 1996. Surface waves in layered anisotropic structures. Geophys. J. Int. 126, 173-183.

Park, J., Levin, V., 2000. Receiver functions from multiple-taper spectral correlation estimates. Bull. Seismol. Soc. Am. 90, $1507-1520$.

Park, J., Lindberg, C.R., Vernon III, F.L., 1987. Multitaper spectral analysis of high-frequency seismograms. J. Geophys. Res. 92, $12675-12684$.

Peyton, V., Levin, V., Park, J., Brandon, M.T., Lees, J., Gordeev, E., Ozerov, A., 2001. Mantle flow at a slab edge: seismic anisotropy in the Kamchatka region. Geophys. Res. Lett. 28, 379-382.
Ribe, N.M., 1992. On the relationship between seismic anisotropy and finite strain. J. Geophys. Res. 97, 8737-8748.

Russo, R.M., Silver, P.G., 1994. Trench-parallel flow beneath the Nazca Plate from seismic anisotropy. Science 263, 1105-1111.

Sandvol, E., Seber, D., Calvert, A., Barazangi, M., 1998. Grid search modeling of receiver functions; implications for crustal structure in the Middle East and North Africa. J. Geophys. Res. $103,26899-26917$.

Savage, M., 1998. Lower crustal anisotropy or dipping boundaries? Effects on receiver functions and a case study in New Zealand. J. Geophys. Res. 103, 15069-15087.

Seliverstov, N.I., 1997. Geodinamicheskaya skhema razvitiya zony sochleneniya Kurilo-Kamchatskoy i Aleutskoy ostrovnykh dug (Geodynamic evolution of the junction zone of the Kuril-Kamchatka and Aleutian island arcs). Vulkanol. Sejsmol. 3, 12-17.

Shapiro, N.M., Gorbatov, A.V., Gordeev, E., Dominguez, J., 2000. Average shear-velocity structure of the Kamchatka peninsula from the dispersion of surface waves. Earth Planets Space 52, $573-577$.

Thomson, D.J., 1982. Spectrum estimation and harmonic analysis. IEEE Proc. 70, 1055-1096.

Van der Hilst, R.D., Engdahl, E.R., Spakman, W., Nolet, G., 1991. Tomographic imaging of subducted lithosphere below northwest Pacific island arcs. Nature 353, 37-43.

Vernon, F.L., Fletcher, J., Carroll, L., Chave, A., Sembrera, E., 1991. Coherence of seismic body waves from local events as measured by a small-aperture array. J. Geophys. Res. 96, 11981-11996.

Weimer, S., Tytgat, G., Wyss, M., Duenkel, U., 1999. Evidence for shear-wave anisotropy in the mantle wedge beneath south-central Alaska. Bull. Seismol. Soc. Am. 89, 1313-1322.

Wessel, P., Smith, W.H.F., 1991. Free software helps map and display data. Eos Trans. AGU 72, 441.

Willett, S.D., Beaumont, C., 1994. Subduction of Asian lithospheric mantle beneath Tibet inferred from models of continental collision. Nature 369, 642-645.

Yu, Y., Park, J., 1994. Hunting for azimuthal anisotropy beneath the Pacific Ocean region. J. Geophys. Res. 99, 15399-15421.

Yuan, X., Ni, J., Kind, R., Sandvol, E., Mechie, J., 1997. Lithospheric and upper mantle structure of southern Tibet from a seismological passive source experiment. J. Geophys. Res. 102, 17491-17500.

Yuan, H., Park, J., Levin, V., 2002. Skidmarks of trench-parallel terrane migration: subduction-zone anisotropy structure under Corvallis, Oregon. J. Geophys. Res. (submitted for publication).

Zhu, H., Ebel, J.E., 1994. Tomographic inversion for the seismic velocity structure beneath northern New England using seismic refraction data. J. Geophys. Res. 99, 15331-15357.

Zhang, S., Karato, S.-I., 1995. Lattice preferred orientation of olivine aggregates deformed in simple shear. Nature 375, 774-777.

Zhang, S., Karato, S.-I., FitzGerald, J., Faul, U.H., Zhou, Y., 2000. Simple shear deformation of olivine aggregates. Tectonophysics $316,133-152$. 